\title{
INTERNATIONAL DONOR AGENCIES’ GUIDELINES FOR RESPONDING TO CHILDREN IN EMERGENCIES
}

\author{
by \\ Nina Angel Prabhu \\ B.Sc.(Hons.) University of Toronto, 2006
}

\author{
A Major Research Paper \\ presented to Ryerson University \\ in partial fulfillment of the requirements for the degree of \\ Master of Arts \\ in the program of \\ Early Childhood Studies \\ Ryerson University \\ Toronto, Ontario, Canada 2007
}

(C) Nina Prabhu 2007 


\title{
INTERNATIONAL DONOR AGENCIES' GUIDELINES FOR RESPONDING TO CHILDREN IN EMERGENCIES
}

\author{
(C) Nina Prabhu, 2007 \\ Master of Arts \\ Early Childhood Studies \\ Ryerson University
}

\begin{abstract}
The document review discusses selected guidelines and recommendations that international actors have formulated as a result of experience providing relief for young children in emergencies. Its purpose is to help develop response plans for future emergencies. The failure to respond to and protect children from escalating threats in emergencies has many consequences including a loss of educational opportunity and a long-term social cost. To prevent these tragedies children's core needs need to be met in safe, protected and structured settings, with support provided for caregivers. Questions addressed in the document review include 'What are international donor agencies' guidelines for responding to young children in emergencies?' and 'What can be learnt from them to plan for future emergencies?' The document review is followed by a discussion of the guidelines and recommendations for the future development of response guidelines.
\end{abstract}

Key Words: young children, early childhood, emergencies, emergency response/relief, and international response/relief 


\section{Table of Contents}

ii Author's Declaration

iii Abstract

iv Table of Contents

$\mathrm{v}$ Abbreviations

1.0 Introduction

1.1 The Realities of Emergencies

1.2 Purpose of Document Review

1.3 Significance

1.4 Research Questions

1.5 Key Terminology

2.0 Methodology

2.1 Approach of Document Review

2.2 Scope

2.3 Sample

2.4 Review Process

3.0 Brief Descriptions of Selected International Organizations

3.1 Save the Children Alliance

3.2 United Nations Children’s Fund

3.3 The World Health Organization

3.4 International Federation of the Red Crescent Societies/ International

Committee of the Red Cross

3.5 Other Organizations

3.6 Child Rights Framework

4.0 Risks to Children and Families in Emergencies

4.1 Health

a) Mental Health

i) Psychosocial Health of Children

ii) Mental Health of Caregivers 
b) Physical Health

i) Infant Nutrition

ii) Nutrition of Older Infants (>6 months) and Young Children

c) Medical Intervention

4.2 Safety
a) Separation
b) Abduction into Armed Forces
c) Sexual Abuse, Exploitation and Trafficking
d) Accidents

4.3 Care

a) Physical Environment

i) Safe Space

ii) Emergency Response Activities for Young Children

b) Care for Caregivers

c) Discrimination and Marginalization

5.0 Recruitment and Training of Personnel

6.0 Material Resources

7.0 Advance Preparation

8.0 Collaboration and Coordination

8.1 The Coordinating Role in Emergency Relief

8.2 Inter-Agency Coordination and Collaboration

8.3 Local and International Coordination and Collaboration

9.0 Assessments, Monitoring and Evaluation

9.1 Assessments

9.2 Monitoring and Evaluation

11.0 Discussion

11.1 Strengths

11.2 Weaknesses and Gaps
a) Consistency
b) Practicality 


\author{
c) Protection \\ d) Groups Missed in Relief \\ e) Displace People Outside of Camps \\ f) Communication \\ g) Development and Relief \\ h) Coordination \\ i) Evaluations \\ j) Resilience-Based and Capacity Building Approach \\ k) Local Involvement \\ l) Context Dependency \\ 12.0 Concluding Remarks and Recommendations \\ 13.0 References \\ Appendix A Chart of Selected International Organizations
}




\section{i. Abbreviations}

\begin{tabular}{|c|c|}
\hline BMS & Breast Milk Substitutes \\
\hline BvLF & Bernard van Leer Foundation \\
\hline CCF & Christian Children’s Fund \\
\hline ECD & Early Childhood Development \\
\hline HIV & Human Immunodeficiency Virus \\
\hline IASC & Inter-Agency Standing Committee \\
\hline INEE & Inter-Agency Network for Emergencies \\
\hline IFRC & International Federation of Red Crescent Societies \\
\hline ICRC & International Committee of the Red Cross \\
\hline IFE & Infant Feeding in Emergencies \\
\hline IGO & Inter-Government Organization \\
\hline INGO & International Non-Government Organization \\
\hline $\mathrm{MoH}$ & Ministry of Health \\
\hline NATO & North Atlantic Treaty Organization \\
\hline NGO & Non-Government Organization \\
\hline PLAN & Plan International \\
\hline SC & International Save the Children Alliance \\
\hline UN & United Nations \\
\hline UNCRC & United Nation Convention on the Rights of the Child \\
\hline UNDP & United Nations Development Programme \\
\hline UNESCO & United Nations Educational, Scientific and Cultural Organization \\
\hline UNHCR & United Nations High Commissioner for Refugees \\
\hline
\end{tabular}


UNICEF United Nations Children's Fund

WHA World Health Assembly

WFP World Food Programme

WHO World Health Organization 


\subsection{Introduction}

\subsection{Realities of Emergencies}

On December 25, 2003, an earthquake measuring 6.5 on the Richter Scale struck the southern city of Bam, Iran, and surrounding villages. Over 26,000 people were killed and eighty five percent of the city was destroyed or severely damaged. One year later, another earthquake and the accompanying tsunami left over 200,000 dead in coastal areas of the Indian Ocean. An estimated one third of the deceased were children. Buildings were destroyed, civilians killed and the survivors were left to piece together what was left of the regions. Of the 500,000 people estimated homeless, a third were children, many of whom were separated from their families (Save the Children (SC), cited in Bernard Van Leer Foundation (BvLF), 2005).

Emergencies, and their consequences, create a wide range of problems experienced at the individual, family, community and societal levels. At every level, emergencies erode normally protective support systems, increase the risk of unhealthy development and tend to amplify pre-existing problems of social injustice and inequality (Inter-Agency Standing Committee (IASC), 2007). Every emergency has potentially devastating effects on the lives of people, especially those most vulnerable such as women, children, and those marginalized in the regions affected.

\subsection{Purpose of Document Review}

The following report is an analytical review of international donor agencies’ guidelines for responding to young children in emergencies. The review discusses the guidelines and recommendations that international actors have formulated as a result of 
experience providing relief for children in emergency situations. Following the review is a discussion of strengths, weaknesses, gaps and recommendations.

This review is part of a project of the Emergencies Working Group of the Consultative Group on Early Childhood Care and Development (CG). Its purpose is to help develop pre-emergency response plans for future emergencies. The intended audience of this document review are international organizations that respond to children internationally in emergency situations. It is important to acknowledge that the guidelines are only a point of reference and that an understanding of the local situation, culturally relevant norms, traditions and practices is essential to inform the specific design and implementation of initiatives (BvLF, 2005).

\subsection{Significance}

The failure to respond to and protect children from escalating threats in emergencies has many consequences. It not only results in personal tragedy but it also carries a long-term social cost, an elevated maternal and infant mortality rate, a loss of educational opportunities and a generation of marginalized youth (SC, 2005). According to IASC (2007), in order to prevent these tragedies it is important to meet children's core needs when emergencies occur. Effective initiatives in emergency relief will help reduce emergency-induced distress in safe, protected and structured settings, while relief and support are provided to caregivers.

\subsection{Research Questions}

This document review will address the questions: 'What are international donor agencies' guidelines for responding to young children in emergencies?' and 'What can be learnt from them to plan for future emergencies?' 


\subsection{Key Terminology}

According to the SC Emergency Liaison Team, an emergency is defined as "An acute crisis threatening the lives and well-being of groups, which is beyond the local and national coping mechanisms, thereby requiring external assistance” (cited in Cuninghame, Hyder \& Kesler, 2001, p.6). This definition covers all types of emergencies including natural as well as man-made. The United Nations Children's Fund (UNICEF) uses the term emergency to include "loud” emergencies, such as natural disasters (floods, earthquakes) and man-made disasters (civil strife and warfare), as well as "silent" emergencies, such HIV/AIDS, extreme poverty, and children living on the streets (Pigozzi, 1999). In this paper only documents pertaining to 'loud' emergencies are reviewed.

The term International donor agencies include organizations and agencies operating internationally in child targeted emergency relief. These include international non-governmental organizations (INGOs) and intergovernmental organizations (IGOs). INGO refers to "organizations which are constituted separate from the government or country in which they are founded" and IGOs refer to "organizations constituted by two or more governments including all United Nations (UN) agencies and regional organizations (International Federation of Red Crescent Societies/ International Committee of Red Cross (IFRC/ICRC), 1995).

Young children aged zero to eight years are the focus of the report (IASC, 2007). Although not all of the guidelines reviewed are limited to this age range, they will be included herein if there is a major focus on this age range. 


\subsection{Methodology}

The following section discusses the approach, scope, contents and process of the document review.

\subsection{Approach of Document Review}

The following document review takes a qualitative approach. In qualitative research the researcher "relies on the views of participants, asks broad, general questions, collects data consisting largely of words (or text) from participants, describes and analyzes these words for themes, and conducts the inquiry in a subjective, biased manner” (Creswell, 2005. p.39). Qualitative research is best suited for research problems in which the variables may be unknown and need exploration or a detailed understanding of a central phenomenon is needed.

A qualitative methodology was used for the document review for several reasons. The review is conducted with texts as sample. The study focuses on understanding and interpreting these texts (i.e., the guidelines developed by various agencies for responding to children in emergencies).

Within the qualitative approach for the document review a historical research strategy was used. Gall and Gall (2004) claim that historical research primarily seeks to discover, not create, data relevant to the research problem in sources (i.e., official documents and relics). “The historical research process systematically searches for data to answer questions about a past phenomenon in order to better understand the phenomenon and its likely causes and consequences (p.413)”. One purpose of historical research is to assist in defining and evaluating alternative future scenarios involving particular phenomena. If it is known how certain individuals or groups have acted in the 
past, it can be predicted, with a certain degree of confidence, how they will act in the future.

Causal inference, the process of concluding that one set of events brought about, directly or indirectly, a subsequent set of events, is also part of historical research. It is believed that researchers cannot prove that one past event caused another, but explicit assumptions can be made that underlie the cause inference concerning sequences of historical events. As researchers learn about the antecedents and successors of a historical event, the more likely they are to discover possible alternative causes and reactions to the event (Gall \& Gall, 2004).

There are three types of sources used for historical research, preliminary, primary and secondary. Preliminary sources are electronic or hard copy indexes of primary and secondary sources. Primary sources are information that has been preserved from the past or that is created to document a past phenomenon by someone who witnessed or participated in it (Gall \& Gall, 2004). Text materials are the most common type of primary source for historical research. Lincoln and Guba (cited in Gall \& Gall, 2004) classify text materials as either documents prepared for personal use (e.g. letter) or records with an official purpose (e.g. policy briefs). Other forms of primary sources include oral history, relics (an object whose physical properties provide information about the past), maps, photographs, journals and diaries. In secondary sources the author describes an event or situation at which the author was not present. They base their accounts on descriptions or records of events generated by other individuals who witnessed or participated in events. For the following document review, preliminary and secondary sources are used. 
The authenticity of documents in a historical approach is determined by internal and external criticism. 'External criticism' is concerned not with the content of the source but whether the apparent or claimed origin (author, place and circumstances of publication) of the source corresponds to its actual origin. All of the documents used in the review were obtained from the author or author organization's official websites. 'Internal criticism' is the process of determining the accuracy of information in the source. Researchers ask questions such as "Is it likely that people would act in the way that the writer described? and Do the budget figures mentioned by the author seem reasonable?” (p.421). The data in the documents collected were compared against each other for internal consistency.

\subsection{Scope}

As specified in Key Terminology, only “loud” emergencies were used and their impact on children aged zero to eight were considered. Guidelines and evaluations covering the period 1999 to the present were included. Several documents obtained were undated; however they were included if details in the document suggest publication post 1999. Issues related to formal education were excluded. Multilateral and bilateral agencies were also excluded that do not have their own initiatives focusing on early childhood. The only exception among them is IFRC/ICRC which is involved in several collaborative efforts in emergencies focusing on young children.

\subsection{Sample}

The documents used were a sample of convenience due to lack of access to other resources. 
Initial contacts with donor agencies were made through the CG. An email message requesting documents pertaining to children in emergencies was sent to agency contacts. Due to the limited response, the researcher proceeded to download relevant documents available from organizations’ websites.

The organizations used in the review were determined according to membership of the CG and a record of collaborative efforts in emergency relief for young children. Organizations identified include SC, UNICEF, Plan, Christian Children’s Fund (CCF) and BvLF. The IFRC/ICRC and the World Health Organization (WHO) were also included for their activity in emergency relief for young children. The documents used were developed by these organizations as evaluations of previous projects, lessons from experience, or guidelines for future response. The large majority of resources used are from SC and UNICEF as they simply have more publications on the topic of interest and are more accessible electronically.

\subsection{Review Process}

In the preliminary round, five documents were briefly summarized and reviewed to identify themes (e.g. health and pre-emergency planning). These themes were then used as key categories for organizing data. New categories were created as they emerged in the research process. Final categories used for the review include: risks that children and families face in emergencies; advance preparation; operational stage response; assessment/ monitoring/ evaluation; and local/international collaboration.

Documents were compared for strengths, weaknesses and gaps. As a result of the review, these are discussed and recommendations are included. 


\subsection{Brief Descriptions of Selected International Organizations}

Refer to Appendix A for the Brief Descriptions of Selected International Organizations in chart format. International actors used in the review include the following:

\subsection{International Save the Children Alliance}

SC consists of several regional bodies with similar but not necessarily the same function. SC focuses their rights-based approach on child protection. The organization seeks to integrate child protection into all of its emergency response programs at every stage of the emergency. The types of protection identified that children need most are: protection from physical harm; exploitation and gender based violence; psychosocial distress; recruitment into armed groups; family separation; abuse related to forced displacement; and denial to access education.

Child Protection includes taking “measures that promote children’s physical and emotional well-being, providing them equal access to basic services, and safeguarding their legal and human rights. After a conflict, protection programs provide long-term support to those who have suffered” (SC, 2005, p.3). The best protection is in preventative measures including strengthening individuals and communities in their abilities to protect themselves (SC, 2005, Cuninghame et al., 2001).

First developed by SC Sweden and now practiced widely in initiatives for young children in emergencies, SC uses a STOP principle in emergency relief. STOP represents:

$$
\begin{aligned}
& \text { S- space and structure } \\
& \text { T- trust, time, talking } \\
& \text { O- opportunities to play } \\
& \text { P- partnership with parents }
\end{aligned}
$$

(Cuninghame et al., 2001; cited in BvLF, 2005) 
SC asserts that approaches to children in emergencies should foster children's natural resilience and an understanding of child development as well as the contextual knowledge of the culture, traditions and political realities (SC, 2005). They also believe that sustainable initiatives involve community- based approaches that encourage self-help and builds on the local culture, realities and perceptions of child development (SC Sweden, n.d (c)).

\subsection{United Nations Children's Fund}

Originally UNICEF was involved only in primary and immediate material support; however with the growing complexity of emergencies they have broadened the scope of their response. UNICEF tends to be more involved in funding emergency programming (Kamel, 2005). Its Core Commitments include: health and nutrition; water, sanitation and hygiene; child protection; education; and HIV/AIDS. To facilitate the commitments UNICEF sets up mechanisms for: security; fundraising and communication; human resources; information technology and telecommunications; supply and logistics; and finance and administration (UNICEF, 2005).

Although other UN agencies (e.g. UN High Commissioner for Refugees (UNHCR) and UN Educational, Scientific and Cultural Organization (UNESCO) have mandates for the care and education of children in emergencies, UNICEF's mandate to protect and assist children in emergencies is broader and more encompassing (Kamel, 2005).

\subsection{World Health Organization}

Through the Department of Emergency and Humanitarian Action, WHO coordinates inputs from other organizations' technical departments with those of 
governments to address core health issues in emergencies for: the assessment of health risks; health coordination; epidemic and nutritional surveillance; control of preventable causes of illness and death; access to basic preventative and protection of health workers; services and structures; and human rights to health and reducing the impact of future crises (WHO, 2007).

\subsection{International Federation of the Red Crescent Societies/International Committee of} the Red Cross

IFRC/ICRC's main contribution in emergency relief is material assistance. They are involved in disaster preparedness, the readiness to reduce the impact of disasters, predicting and even preventing disasters from occurring, and disaster management in relief operations. The aim in relief operations is to provide life-saving assistance, shelter, water, food and basic healthcare and immediate needs. Long-term initiatives IFRC/ICRC are involved in include reconstruction and rehabilitation (IFRC/ICRC, 2007).

\subsection{Other Organizations}

Other organizations that participate in emergency relief for young children are BvLF, CCF and Plan. These organizations provide relief and support targeting poverty from a child-centered approach. Support is provided for the holistic (physical, social, emotional, intellectual, cultural and spiritual) development of the child (CCF, n.d, BvLF 2005 and Plan 2007a,). These organizations are not as large scale as SC and UN agencies. However they have significant involvement internationally with emergency response for young children. Despite focusing on children 0-6 years, the programmes of these organizations are not labeled as 'early childhood development (ECD) emergency 
interventions' as they are designed as part of a larger package of holistic humanitarian support interventions (Kamel, 2005).

There are many similarities in approach amongst the organizations mentioned above. They all use a rights based framework advocating the United Nation's Convention on the Rights of the Child (UNCRC) to target child protection, health and education. SC, BvLF, CCF and Plan also provide early childhood care, parental education, and pre-primary classes for children affected by emergencies.

\subsection{Child Rights Framework}

The guidelines will be reviewed from a Children’s Rights moral framework according to the UNCRC (UN, 1989). Although the UNCRC does not imply a legal responsibility, the document identifies a moral obligation by signed members to uphold children’s right to survival, right to protection and right to develop (Castelle, 1990).

The UNCRC framework assigns responsibility to society, including donor agencies, for the well being of children when providing emergency relief (BvLF, 2005). Most significantly, the document defines children's welfare in terms of international justice rather than charity. Various areas of the UNCRC will be identified in the review as it directly relates to the themes of emergency relief for young children.

It must be noted that there is some risk associated with taking a child rights based approach universally. When the child rights framework conflicts with cultural norms, some communities may feel that their traditional values and customs are under pressure due to the emergency. Some rights based interventions may directly confront traditional ways of treating certain groups which may be considered as discrimination according to 
the UNCRC (BvLF, 2005). Therefore notions of children's rights may need to be introduced in culturally appropriate ways and not imposed.

The content of the following sections, Risks to Children and Families in Emergencies, Recruitment and Training of Personnel, Material Resources, Advance Preparation, Collaboration and Coordination and Assessments, Monitoring and Evaluation, are recommendations for emergency response by the selected organizations and documents used in the review. Suggestions for guidelines by the researcher based on the selected documents reviewed are included in the Discussion and Concluding Remarks and Recommendations sections.

\subsection{Risks to Children and Families in Emergencies}

In the following section, risks children and families in emergencies face along with accompanying emergency response are discussed. Topics include health, safety, and care.

\subsection{Health}

a) Mental Health

i) Psychosocial Health of Children

According to Article 39 of the UNCRC, the State has the responsibility to promote the physical and psychological recovery and social re-integration of child victims of abuse, neglect, exploitation, torture and armed conflict. This shall be conducted in an environment which fosters the health, self-respect and dignity of the child (UN, 1989). 
Children's responses to emergencies vary from child to child and are highly individual in nature. They are often quite intense (WHO, 2001; Cuninghame et al., 2001) but most of the distress starts early and subsides within weeks or months. Onset may also be delayed or reactions may be long-term leading to considerable disability (SC UK \& UNICEF, 2006).

One of the initial signs of emotional disturbance is children's inability to socialize and play with contemporaries (UNESCO, cited in Kamel, 2005). Children may withdraw from contact with others, stop playing and laughing, or become obsessed with violent war games. They may dwell on feelings of guilt or fantasies of revenge, or they may have a continual pre-occupation with their role in the emergency and feel responsible for past events. SC Sweden (n.d) claims psychological distress might manifest itself in flashbacks of stressful events and the inability to concentrate. Sometimes children express symptoms of illness (e.g. headaches, vomiting or fever) (Washington State Department of Health, 2006). Toddlers may respond to distress by regressing in behaviour (thumb sucking), becoming mute, or engaging in clinging behaviour. They may also have a loss of appetite, become easily irritated or have an exaggerated startle response (Plan, 2007d). SC Sweden (n.d (c)) claims that distress may manifest as aggressiveness, eating disturbances, learning problems, or physical ailments. Children’s distress can take many forms and expressions. However it is recommended that no manifestation should be dismissed as 'naughtiness'.

Some guidelines suggest that children often express their distress at nighttime. Some children have nightmares, express fears of the dark or sleeping alone, or revert to bedwetting (Washington State Department of Health, 2006, Plan (d), 2007). Children 
who had experienced the 2004 tsunami said they were simply afraid close their eyes and were unable to sleep for fear that the traumatic event will occur again or that they would lose their family (SC, 2005).

Losing trust in adults is a primary casualty of emergencies. The primary caregiver, often the mother, can be so affected by the material impact that she is unable to meet the child's basic needs including those of food, shelter, and protection. SC suggests it is vital to rebuild a child's belief that he/she can trust and rely on adults to provide love, food and shelter (Cuninghame et al., 2001).

Certain experiences leave children at greater risk for maladaption to emergencies. Specific traumatic events experienced that were identified to have lasting effects were those involving family members (e.g. witnessing a sibling drowning or being abducted). In a SC UK and UNICEF (2006) flood response evaluation, children expressed that they live in constant fear of something bad happening to them or someone they love. This prolonged fear is detrimental to children's health and development.

In guiding principles developed after the 2004 tsunami by the International Rescue Committee, SC UK, UNICEF, UNHCR and World Vision International (cited in BvLF, 2005), it is suggested that trauma counselling after an emergency should never be provided unless there are appropriate and sustainable follow-up procedures in place. There are serious risks associated with trauma counselling when provided by nonprofessionals such as re-traumatization. It is also suggested that trauma counselling never be the starting point for emergency response (SC Sweden, n.d (c)).

In the context of counselling, children must have the opportunity to express themselves verbally and non-verbally. Cuninghame et al. (2001) claim that exploring 
children's feelings will help reduce guilt and fear. Activities such as drawing and makebelieve play may cause children to recall and express distressing memories. It is suggested that such expressions be neither encouraged nor discouraged, but allowed and supported if initiated by the child.

Most children will cope well once basic needs are met and safety, stability and opportunities to play are restored within social and family contexts. Cuninghame et al. (2001) suggest that appropriate psychosocial support be provided as soon as possible to avoid the prolonging of distress. Personnel should not wait until material needs are met. There must also be referral systems in emergency relief for the minority of children severely affected to receive additional support. SC UK (2006) points out that young children can cope with the stress of an emergency and consequences if their parents, or other close adults, can sustain a strong attachment and project stability, permanence and competence.

\section{ii) Mental Health of Caregivers}

Often the most profound impact from an emergency is that caregivers, usually mothers, grandmothers and older siblings, are unable to meet children's needs for nurturing and support (Kamel, 2005). Caregivers may be absent or physically and emotionally exhausted (Williams, 2005, IASC, 2007). They may be unable to utilize normal support networks in times of familial need (Williams, 2005) or unable to provide effective care, routine and support (IASC 2007). Without proper support, caregivers' short-term problems may lead to longer depression or other psychological conditions (SC, 2005). 
The critical factor that promotes children's resilience is not only the physical availability of a primary caregiver but also their emotional availability. Emotional availability can deteriorate as a result of caregiver depression resulting from prolonged stress in times of crisis (Kamel, 2005).

SC (2005) suggest that caregivers who have difficulties in caring for their children because of severe mental health problems be referred to receive appropriate support from health services staff.

b) Physical Health

i)Infant Nutrition

Article 24 of the UNCRC regarding Health and Health Services outlines that States have the responsibility to (a) diminish infant and child mortality, (b) combat disease and malnutrition, (c) ensure appropriate pre- and post natal health care for expectant mothers and (d) provide education and support in the use of basic knowledge of child and health nutrition, breast feeding, hygiene and environmental sanitation (Castelle, 1990).

Infant feeding practices have become increasingly important to emergency relief. Under the pressures of a crisis, caregivers are often confused, misinformed or uninformed about what is best for their children.

There is a common misconception that mothers can no longer breastfeed accurately due to stress and inadequate nutrition in emergencies, hence the need for infant formula and other milk products (UNICEF \& IFRC/ICRC, n.d). In interviews conducted in post-crisis Kosovo by SC (1999), the perceived inadequacy of breast milk was the main reason given for the cessation of breastfeeding in all age groups. However, 
according to the Infant and Young Child Feeding in Emergencies (IFE) Core Group (2006), in most emergencies replacement feeding or the early cessation of breastfeeding is unlikely to be acceptable, feasible, affordable, sustainable, or a safe option.

Unanimously, the guidelines suggest that emergency relief must primarily promote continued breastfeeding (IASC, 2007, UNICEF \& IFRC/ICRC, n.d, SC UK, 1999, IFE Core Group, 2006). UNICEF and IFRC/ICRC (n.d) claim that stress can temporarily interfere with the flow of breast milk; however, it is not likely to inhibit breast milk production if mother and infants remain together and are supported to initiate and continue breastfeeding. There is the risk that lactating mothers become malnourished and are rendered unable to breastfeed, but with adequate fluids this risk is decreased. It is recommended that conditions in emergency relief be created to facilitate breastfeeding (e.g. safe corners or helping mothers to re-lactate).

Evaluations conducted in post-crisis Kosovo point out that there should be more investigation into the acute and chronic effects of crises on lactation. The practicalities of re-lactation in emergency situations should also be assessed as women expressed frustration and discouragement trying to relactate in crises (WHO, 2003).

Breastfeeding is optimal for the physical, psychosocial and cognitive well being of infants and toddlers. It comforts the child and is likely to strengthen the mother-child bond (IASC, 2007). Breastfeeding provides valuable protection from infection, especially in environments without safe water and sanitation (UNICEF \& IFRC/ICRC, n.d). Continued breastfeeding into the second year of life is likely to provide the best chance of survival for infants and young children in emergencies. 
UNICEF and IFRC/ICRC (n.d) claim that no food or liquid other than breast milk, not even water, is usually needed to meet infants’ nutritional requirements during the first six months of life. After six months, it is recommended that infants begin to receive a variety of foods while breastfeeding continues up to two years or beyond.

The IFE Core Group (2006) suggests that women who test positive for the human immunodeficiency virus (HIV) be supported to make informed decisions about infant feeding. The risks of infection or malnutrition from using breast milk alternatives are likely to be greater than the risk of HIV transmission through breastfeeding.

The IFE Core Group (2006) recommends that feeding support and training be integrated at all levels of health care including: anti- and postnatal care; family planning; traditional birth attendants and maternity services; immunization; growth monitoring and promotion; curative services; selective feeding programmes (supplementary and therapeutic); and community health services. This integration would involve working with all local agencies.

Breastfeeding can be promoted through individual support and community dialogue. IASC (2007) recommends that mothers and relatives of newborns be informed about newborn care, exclusive breastfeeding and other nurturing activities (e.g. wrapping and warming babies, deferred bathing and hygiene). Caregivers who refuse to breastfeed, finding it difficult, or cannot breastfeed must also receive support. Specific expertise on breastfeeding counselling and support could be sought at the national level via Ministry of Health (MoH), UNICEF and WHO, or at the international level via International Lactation Consultancy Association, WHO and UNICEF. 
IASC (2007) suggests that there must be supports in place for the immediate nutritional and care needs of orphans and unaccompanied children. Newborns and infants separated from their mothers need to have their basic needs for food, warmth, and care met. UNICEF and IFRC/ICRC (n.d) recommend that alternative feeding methods follow cultural norms and, if acceptable, wet nurses could be used.

According to the IFE Core Group (2006), there should be no general distribution of breast milk substitutes (BMS). The decision to accept, procure or distribute infant formula in an emergency must be made by informed, technical personnel in consultation with coordinating agencies, led by technical agencies and governed by strict criteria. BMS should be distributed based on careful needs assessments and used under strict medical control, monitoring and hygienic conditions. Distribution must be in accordance with the International Code of Marketing of Breast Milk Substitutes, World Health Assembly (WHA) resolutions, and agencies’ policies and guidelines.

The IFE Core Group (2006) recommends that donated (free) formula or subsidized BMS be avoided unless all of the following three conditions stipulated by WHA resolution 47.5 (1994, cited in IFE Core Group, 2007) apply: a) infants have to be fed BMS as a result of the health and socioeconomic circumstances outlined in WHA resolutions (e.g. absent or dead, very ill, re-lactating, and HIV positive who has chosen not to breastfeed mother, infant rejected by mother or artificially fed prior to emergency, and rape victim not wishing to breastfeed); b) the supply of BMS is continued for as long as the infants need it; and c) the supply is not used as a sales inducement (IFE Core Group, 2006). SC (1999) suggests that the availability of fuel, water, and equipment for safe preparation of BMS always be assessed prior to distribution. If artificial feeding is 
required cups, not bottles, should be used. It is also recommended that areas for artificial feeding be in an area distinct from breastfeeding support. The IFE Core Group (2006) recommend that there be special support for new mothers and women who might be building up a breast milk supply using artificial and breastfeeding methods during relactation. Care should also be taken so that stigma is not associated with BMS use. Within the UN IASC cluster approach to humanitarian response, UNICEF is likely the UN agency responsible for the coordination of IFE in the field (IFE Core Group, 2006). UNICEF is responsible for the supply of generically labeled infant formula and mobilization of therapeutic milk and breast milk substitutes in the treatment of severe malnutrition (SC UK, 1999)

The IFE Core Group (2006), recommended that the distribution of BMS be linked to other support. There should be education, one-to-one demonstrations and practical training about safe preparation. There should be follow-up at the distribution site and at home by skilled health workers for regular infant weight monitoring no less than twice a month. According to the IFE Core Group manual on Infant and Young Child Feeding in Emergencies (2006), with infant formula distribution, UNICEF will train and support agencies in training staff and mothers on safe use and preparation.

BMS, other milk products, bottles and teats must never be included in general distribution. According to the IFE Core group (2006), any well-meant but ill-advised donations of BMS, bottles and teats should be collected from all ports of entry by recipient agencies, stored centrally under the control of a single agency and guided by a coordinating body. A plan for the safe use, monitoring, or eventual destruction, will be developed by UNICEF to prevent indiscriminate distribution. One alternative use of 
BMS donations is to mix it with a milled fortified staple as a complementary food in distribution to make porridge for children over six months.

The IFE Core Group (2006) suggests that each agency at the central level endorse or develop a policy that addresses: infant and young child feeding in emergencies, stressing protection, promotion and support of breastfeeding and adequate, timely complementary feeding; procurement, distribution and use of BMS, milk products, commercial baby foods and infant feeding equipment in compliance with the International Code and WHA Resolutions. It is also recommended that an action plan be developed for emergency relief that identifies agencies’ responsibilities and mechanisms for accountability. The policy and action plan should be disseminated to operational and non-operational agencies including donors and the media.

The IFE Core Group (2006) also recommends key information be obtained in the early stages of emergency relief through routine rapid assessments. Key information includes: a demographic profile, specifically noting whether women (pregnant and nonpregnant) and infant, young and unaccompanied children are under or over-represented; predominant feeding practices (e.g. early initiation of exclusive breastfeeding and wetnursing); conspicuous availability of BMS, milk products, bottles and teats and breast pumps; commodity pipeline; problems feeding infants and young children (e.g. breastfeeding problems and poor access to infant complementary foods); pre-emergency approaches to feeding orphaned infants; and security risks to women and children.

ii) Feeding of Older Infants ( $>6$ months) and Young Children

It is recommended that foods suitable to meet the nutritional needs of older infants and young children be included in the general ration of food aid. It is also advised 
that special attention be given to the nutritional value of the food ration distributed to infants and young children whose particular nutrient requirements are often not covered by the general ration (IFE Core Group, 2006).

IASC also suggests that an educational component should be an integral part of every project, especially where supplementary food commodities are distributed. Health and nutrition staff will require technical training involving provisions for young children (IFE Core Group, 2006).

Young children have specific nutritional needs according to their stage of development determined by age. SC UK (1999) points out that older infants (>6 months) and young children (12 to $<24$ months) require nutrient-rich and energy dense foods in addition to breastfeeding. Specific food for young children should be included in the general ration, blanket or supplementary feeding.

The guidelines provide several examples of complementary foods for young children. Examples include fortified foods, micronutrient supplements (e.g. Vitamin A or zinc) (UNICEF \& IFRC/ICRC, n.d) or blended micronutrient foods (e.g. corn soya blend and wheat soya blend). Complementary infant food (e.g. fruits and vegetables) and basic food commodities (e.g. rice, beans and lentils) can be found locally produced. The use of manufactured complementary products is discouraged (SC UK, 1999, IFE Core Group, 2006).

According to UNICEF and IFRC/ICRC (n.d), for children that are severely malnourished, milk-based therapeutic foods should be provided with close supervision by specialized agencies and trained personnel following strict protocols. 
The IFE Core Group (2006) suggests that in situations where supplementary foods are available but are insufficient for the general population, pregnant women should be given priority.

\section{c) Medical Intervention}

According to the UNCRC, Article 24 states that children have the right to the highest attainable standard of health. The State shall take appropriate steps to diminish infant and child mortality, ensure necessary medical assistance and health care, combat disease and malnutrition, and ensure health for expectant mothers (UN, 1989).

Prior to the onset of an emergency, children differ in their general health, nutritional status, and exposure to communicable diseases regionally. According to WHO (2003), these differences persist and determine the type of health interventions needed in emergencies. However, they recommend relief also be flexible and adaptable because health and nutritional needs also vary in the post-emergency phase due to the combined impact of an increased incidence of communicable diseases, diarrhea and malnutrition. According to WHO (2003), interventions should be prioritized at all levels in the health care system (e.g. community and hospital) to reduce excess child mortality and morbidity in emergencies.

WHO (2003) identifies several major causes of child morbidity and mortality in emergencies. Major causes include diarrheal diseases, acute respiratory tract infections, malaria, measles and malnutrition. The most notable contributors were micronutrient deficiencies. Depending on regional, local epidemiology or the nature of the emergency, other potential risks include meningococcemia, pertussis, leishmiasis, tuberculosis and dysentery, HIV/AIDS, physical and sexual abuse, and psychosocial health problems. 
Often the right interventions are implemented to reduce child mortality and morbidity in emergencies, but not at the right time.

WHO (2003) advises that emergency interventions include diarrhea prevention, oral rehydration therapy, food security and feeding programmes for malnourished infants, measles immunization, and vitamin A supplementation.

UNICEF (2005) is responsible for several health interventions in emergencies. In the first six to eight weeks UNICEF will vaccinate all children between six months (at least six months) and fourteen years of age against measles. They will also provide vitamin A supplementation, treatment for malaria, diarrhea and pneumonia, essential drugs, emergency kits, fortified nutritional products and micronutrient supplements. UNICEF will also support the establishment of essential health-care services by providing outreach services, home-based management of childhood illnesses, and emergency obstetric care services.

Several resources have been developed targeting child health intervention in emergencies. These include: The Integrated Management of Childhood Illnesses; Training for Improved Practice in Public Health in Nutrition and Emergencies by UNICEF, Centers for Disease Control, Tufts and Columbia University; WHO Communicable Disease Working Group on Emergencies (CD-WGE) training modules specifically targeted at communicable disease control in complex emergencies; and Building the Evidence Base on the Provision of Health Care to Children in Complex Emergencies by WHO and John Hopkins University (WHO, 2003). However, limitations in optimal use of these guidelines include: length of training required for understanding and resource use; inadequate or non-functioning health facilities with limited staffing; 
limited staff capacity and supervision; poor coordination; insufficient links with communities; lack of security for the delivery of services; and limited accessibility to guidelines in the field. The unpredictability and lack of stability in emergency situations are also limiting factors.

WHO (2003) identifies other obstacles in providing health care to children in emergencies. Obstacles include physical barriers (e.g. weak, overburdened or nonexistent health care systems); behavioural and cultural barriers (e.g. cultural beliefs about illness or gender-specific constraints); and financial barriers (e.g. fees for services or medicine for populations that do not have the resources to pay). Additional obstacles include: decreased health system uniformity; difficulties ensuring comprehensive, coordinated and appropriate care with multiple organizations; different referral services; lacking or insufficient supply and delivery systems; and minimally trained health care primary providers. Also, SC (n.d) mentions that deaths from non-violent causes (e.g. infectious diseases) are highest in conflict-prone regions where security problems affect access to healthcare and humanitarian assistance.

WHO (2003) makes some suggestions for overcoming the obstacles above. Emergency relief could strengthen the capacity of non-traditional health care systems (e.g. communities and households) to respond to illness. Alternative methods and strategies to service delivery could be developed (e.g. using private providers for antibiotics or scaling up the delivery of nets for malaria control) to increase access.

\subsection{Safety}

CCF claims that the greatest stresses arise not from violence or natural disasters but from difficult life conditions that follow (cited in BvLF, 2005). 


\section{a) Separation}

Priorities in emergency relief are keeping families together, preventing separation, and promoting child protection. The IASC (2007) advises that when separation does occur, all efforts should be made to reunify children and caregivers.

There are accidental and deliberate ways children can be separated from their families in emergencies. Accidental separations include: children wandering from their parents/caregivers; separation during flight; fleeing when their home is attacked; death or injury of family members; capture or arrest of family members; mobility limitations due to disabilities; and gathering by police or other personnel of children thought to be separated (BvLF, 2005). Other accidental separations are caused by haphazard and unplanned evacuation and lack of preparedness (SC UK \& UNICEF, 2006). Separation may also be a choice by parents/caregivers or child. Cause of deliberate separation include: family stress (e.g. poverty, famine, or the breakdown of informal welfare or extended family structures); death or disability of parents; abandonment during flight; families handing their children over to others for safety; and children being left behind by foster families (BvLF, 2005).

SC (Sweden, n.d (a); 2005) suggests that children who have been separated from their immediate family be identified as quickly as possible. It is also suggested that a plan including immediate, long-term solutions and monitoring be developed for children whose families are not found.

If children are separated, initial steps of registration and documentation must be made. Initial steps include contacting the proper reunification organization, recording the date and place the child is found, collecting information from children using age 
appropriate methods (e.g. drawing pictures of families and where they lived), keeping clothing with the child (i.e., key means of identifying and reunifying separated children and their parents) (IASC, 2007), and taking pictures of the child and their possessions. The extent of family separation and immediate arrangements should also be recorded. Registration is key to avoiding the possibility that family tracing will be undermined in cases of spontaneous fostering (SC Sweden, n.d (a)). BvLF (2005) suggests that registration activities should only be conducted by or under the direct supervision of government authorities or mandated agencies that have experience with separated children.

Families that have been separated from their children usually have the ability to search for them through tracing services provided by the ICRC. If families and children are reunited, verification processes must be in place to validate the relationships between the child and family (BvLF, 2005).

When children are separated from their families, SC Sweden (n.d (a)) recommends that aid agencies and governments make alternative care arrangements in the best interests of the child. Care arrangements for children could include temporary centres until long-term solutions are identified (IASC, 2007) or fostering with an individual or family that can provide appropriate care and protection. BvLF (2005) suggests that the separation of siblings be avoided and arrangements for one continuous foster family be made rather than multiple foster families. Orphanages should be viewed as the last resort as they do not usually provide appropriate support (IASC, 2007). Organizations agree that adoption should be the last option when tracing methods are exhausted but when it does occur it must be in the best interests of the child and apply to 
national and international law. However, SC Sweden claims (n.d (a)) that children in emergencies are not available for adoption according to international agreements.

A number of agencies claim that community care arrangements serve children’s emotional well-being best (SC Sweden, n.d), provide continuity and socialization (BvLF, 2005) and are likely to increase recovery in times of distress (SC, 2005). Naomi Richman (2005) also writes that for all children, the presence of at least one familiar person who provides continuity is essential in re-establishing trust after an emergency. Most separated children have parents or other family members that are willing and able to care for them and can be found with effective tracing (SC Sweden, n.d (a)).

Monitoring is essential during temporary care and fostering arrangements. Monitoring is needed to avoid discrimination against and exploitation of children (SC Sweden, n.d (a)). BvLF (2005) claims some families may accept to care for children with the intention of exploitation for labour purposes. According to WHO (2003), there is an increased risk of domestic violence accompanying the frustration, fear and stress of separation (SC, 2005; SC UK \& UNICEF, 2006). Also, families may change with time and children may no longer be wanted by their families when they are reunited (SC UK and UNICEF, 2006).

According to the Inter-Agency Guiding Principles on Unaccompanied and Separated Children (cited in BvLF, 2005), separated or accompanied children that need emergency attention can also be found in a variety of 'spontaneous care arrangements'. Spontaneous arrangements include living with: extended family; unrelated families including friends; neighbours and even strangers; and in group-living arrangements 
formed by children themselves including sibling-headed households. These children may not be classified as 'unaccompanied' but may require significant protection and care.

In emergencies the identification of separated or unaccompanied children may be difficult. Communities may be suspicious when answering outsiders' questions regarding children. Families may not want to give information as they take children in for other benefits (e.g. labour) and do not want to lose them. Children may also fear that by being identified they will be stigmatized or separated from their siblings (BvLF, 2005).

There are several initiatives that can be implemented to prevent separation. The IASC (2007) recommends tagging children at registration and assessments in the initial phases of emergency response. Families and children in Bangladesh suggest that families and agency personnel can teach older children songs that include their family name, village and contact information. Shelters could be organized so members of the same family stay together and families that know each other share rooms. Children should also be advised to resist the temptation of food or sweets offered by anyone unless it is approved by their adult guardians or some familiar trustworthy elder (SC UK \& UNICEF, 2006).

\section{b) Abduction into Armed Forces}

In conflict emergencies, there is a risk of abduction for child soldiering. According to the UNCRC Article 38, no child under fifteen shall be recruited into armed groups or have direct part in hostilities (UN, 1989). In conflict regions, children as young as seven years old have been recruited into armed groups. 
Secondary consequences to conflict may sever children's ties with their families no longer permitting them to return home. Abductors into armed forces may force children to watch or commit atrocities against families and communities to sever ties to a former life. Children may be distressed by what they had witnessed in conflict (e.g. death) and feel powerless to protect themselves and their families (SC, 2005). Also, children reintegrated into communities in Northern Uganda claim that families and communities stigmatize children that have been abducted into armed groups (Fine \& Nix, 2007).

Measures for community reintegration must be a priority. Although there is a Dearmament, Demobilization and Reintegration (DDR) program for former combatants supported by the UN Development Programme (UNDP), the World Bank and the UN Department of Peace Keeping Operation, reintegration of child soldiers is primarily left to NGOs and UNICEF, and is invariably under-funded. Those at the end of the queue for reintegration programs are children and at the end of that queue are girls (SC, n.d). c) Sexual Abuse, Exploitation and Trafficking

According to the UNCRC, article 35 states that States shall prevent the sale, trafficking or abduction of children in any form (UN, 1989).

A man in Mekong Delta in 2001 said "Shortly after the severe flooding some men came to the village and offered me fifty dollars for every girl I could give him, the girls were to be sent to Taiwan as domestic workers” (SC, n.d (a)). Amongst the chaos, instability, and lack of security, children run a high risk of exploitation, abuse, gender violence, and abduction in emergencies. From the evaluation in Bangladesh, it has been identified that children outside of shelters and camps are more at risk of abduction than 
those living in shelters (SC \& UNICEF, 2006). Whenever abuses occur, rape and sexual assault are always underreported because of the stigma attached to these (SC, n.d).

Security in shelters is a necessity for young children. The children in Bangladesh recommend that police and other officials have a code of conduct developed and be sensitized about child protection issues. It is also recommended that all relief workers carry identification, be professionally accountable, and be encouraged to report on colleagues if necessary (SC UK and UNICEF, 2006).

\section{d) Accidents}

Accidents are very contextually dependent but when they do occur they are often disabling. Children in conflict or post-conflict zones have a serious risk of injury from landmines. Children often do not see warning signs and landmines often look like toys and attract young children (BvLF, 2005).

\subsection{Care}

\section{a) Physical Environment}

The physical environment for children has the potential to provide elements of predictability and stability more quickly than any other condition. The quality of the physical world influences children's health, happiness, and long-term development. Any reduction or neglect has long-term implications for children's capacity to cope and thrive (SC Sweden, n.d (b)). A healthy physical environment promotes privacy and social interaction as well as play and recreation. A good environment is primarily interpreted as the right to security. Unfortunately it has been identified that the most pervasive violations of children's rights are related to their living conditions (SC UK \& UNICEF, 2006). 
Children and families should be involved in developing the physical environment. SC Sweden (n.d (b)) claims that involving children gives them an active role in their own and the community's well being. Benefits for involving children include the development and application of skills, knowledge and experiences, and also increased self-esteem. Involvement is a constructive way to channel young person's energies to socially valuable initiatives in communities, thereby acting for their own rights. When families and communities are involved in developing healthy physical environments for their children, benefits are far-reaching (e.g. programme sustainability).

SC Sweden (n.d (b) claim that the very design of structures or shelters has an impact on children's feeling of security. When windows are facing playgrounds children feel safer. Greater safety is also conveyed when entries and gates are facing places where people are moving around as opposed to isolated places.

According to SC Sweden (n.d (b)), emergency assessments for physical factors are seldom systematically taken into account. To a large extent assessments depend on the assessor's knowledge and awareness of environmental issues. Emergency relief tends to focus on the provision of services and underestimates the full extent of the role of the child's physical environment.

\section{i) Safe Space}

A necessary provision in emergency relief for children is safe space. The concept is identified with different names such as ‘child-friendly spaces' (Plan, 2007a) and 'child centered spaces’ (CCF, 2007). For this review ‘safe spaces’ is used.

Safe space is a key provision in emergency relief for children. According to CCF (2007), safe space supports social integration while allowing children to play safely and 
express themselves. It is also used for providing basic health care, supplemental feeding, and other developmental necessities (CCF, n.d).

The location of safe space in camp is critical to relief effectiveness. Cuninghame et al. (2001) suggests that common sense and communication be used to determine locations of relief activities in camp. It is recommended that they be away from armed areas, not on main roads, and located near Mother-Child Health (MCH) services to enable the two closely related activities to complement each other.

Safe space does not have to reside within an enclosed structure but it is recommended to have sufficient ventilation and light. It could consist of a tent at least fifty square meters (for twenty children and a few adult staff) and if possible have additional space for future playground activities and creative use of space (Cuninghame et al., 2001). Separate areas should be set up for pregnant women where doctors and nurses can administer treatment (SC UK \& UNICEF, 2006).

ii) Emergency Response Activities for Young Children

Article 31 of the UNCRC outlines the right to rest and leisure, to engage in play and recreational activities and to participate freely in cultural life and the arts. The State is to encourage the provision of appropriate and equal opportunities for cultural, artistic, recreational and leisure activity (Castelle, 1999).

Cuninghame et al. (2001) suggests that ECD activities be started, in or outside of camps, a few days after some of the other donor responses, such as material assistance, family tracing and protection, have begun.

It is recommended that ECD activities include children two to seven years, boys and girls, and their caregivers (Cuninghame et al., 2001; IASC, 2007). It is advised that 
time and activities are organized according to children's age/stage of development. Groupings include: less than 12-18months (pre-verbal, non ambulatory), 12/18 months- 3 years, and 3-6 years (IASC, 2007). All children must have access each day, using rota systems or dividing children into groups if necessary. It is suggested that rota systems be regularly reviewed and updated (Cuninghame et al., 2001).

Activities must be inclusive. According to the UNCRC Article 2, children have the right to freedom from discrimination (UN, 1989). Article 23 states that disabled children have the right to active participation in the community while receiving services leading to the fullest possible social integration and individual development (Castelle, 1990). Activities must include children with disabilities, minority, and marginalized groups (Cuninghame et al., 2001; IASC, 2007; IFE Core Group, 2006). A positive attitude must be demonstrated towards all children (IFE Core Group, 2006). Activities must include all refugees including those internally and externally displaced and inside and outside of camps (i.e., under siege and hiding) (Cuninghame et al., 2001).

There should be a range of activities provided for children. It is suggested that they be organized without stereotyping for boys and girls and with psychosocial considerations (refer to Psychosocial Health of Children and Recruitment and Training of Personnel). Essential conditions for activities include age appropriateness, clarity of rules and directions, and practicality (Cuninghame et al., 2001; IASC, 2007). Variety is essential for the participation of all children (SC, 2006b). Opportunities for active play, stimulation, and socialization must be organized (IASC, 2007).

Activities should be normalizing to create comfort and some sort of calmness in the chaos. According to IASC (2007), they should reflect children's daily activities (i.e., 
a child from a nomadic background who has never been to school may find formal education neither normalizing nor comforting), developmental milestones (e.g. rites of passage rituals), and promote social community building and non-violence in violenceaffected communities.

There are several important elements in emergency relief for young children. First, opportunities to play are essential (Cuninghame et al., 2001, Inter-Agency Network for Education in Emergencies (INEE), 2004). These could be organized group activities (e.g. games, dancing and singing) and individual activities (e.g. reading, drawing and playing). SC (2005) suggests that known games, dances, local songs, fables, and stories be considered. Children need opportunities to use their imagination, social skills, and spontaneity. They also need time to re-establish trusting relationships through talk, play, and other means of communication (e.g. drawing and role play).

Games and toys allow children to utilize and develop fine and gross motor skills, stimulate intelligence, and begin psychological recovery (Vargas-Barón \& Bernal Alarcón, 2005). SC UK (n.d (b)) claim that stories help stimulate emotions, learn about language, and spark imagination. Children can learn about language, mathematical concepts, rhythmic movement and art in musical activities. They can also be transferred outside of the emergency response initiatives with low cost materials in the home. Educational activities develop children's communication and interaction skills. They give children a proactive role in their learning process and expose children to decisionmaking, responsibility and problem solving.

Communities can be involved in initiatives for young children. According to Plan (2007b), children can care for younger children, gather resources for activities, distribute 
water and food, help in health clinics and make toys. Adolescents can help support younger children. Adults in the community with skills for activities can be identified to help.

\section{b) Care for Caregivers}

Support for families must be integral to emergency relief. It is essential that families are welcomed in activities and able to participate as little or as much as they choose. Cuninghame et al. (2001) suggests that families be given opportunities to do everyday family activities together (e.g. preparing a snack or meal, going for a walk, and singing songs). And opportunities should be provided for elders and older siblings to play and do things together. Parents, siblings, grandparents and youth can be guided to work with available staff and to take learning home to their families (IASC, 2007). It is suggested that in small family group activities, parents have the opportunity to learn from the interactions of other caregivers and their children. Positive parent-child interactions could be pointed out to encourage other parents to interact with their own children in a similar manner.

IASC (2007) recommend that support be provided for parents experiencing stress, including knowing how to control, regulate and modify aggressive behaviours. They recommend identifying harmful responses to children (e.g. beating, abandonment, and stigmatization) and suggesting alternative responses and coping strategies to parents and community leaders.

Caregiver well being is important for child well being. IASC (2007) suggest that parents and other caregivers need opportunities to talk or just sit and feel safe. They need opportunities to express their hopes, fears and concerns. It is suggested that meetings be 
provided so caregivers can discuss the past, present and future, share problem solving, and support one-another in caring.

\section{c) Discrimination and Marginalization}

All guidelines reviewed suggest that discriminated and marginalized populations in regions of emergencies must be specifically identified and included in emergency relief (INEE 2004, Cuninghame et al., 2001).

There is an accumulation of risk for children living in poverty and those who suffer discrimination and social marginalization. For example in emergencies the risks for children living on the streets are additively increased. Discriminated against and marginalized children may be moving amongst categories of risks in emergencies (BvLF, 2005).

In some cultures female children may be at greater risk for neglect.

Children with disabilities often face marginalization in emergency response. Personnel working with children have been found to focus support on the disability of children with special needs instead of the children's personalities (BvLF, 2005).

\subsection{Recruitment and Training of Personnel}

A significant determinant of the quality and effectiveness of emergency relief is the personnel employed by aid agencies. It is suggested that it is best if those who work with children in emergencies are from the children's own culture, share the same language (IASC, 2007) and are female (Plan, 2007b).

Personnel should be recruited from the local population. Organizers should search for people who have experience with young children (e.g. teachers, parents, elders or individuals with younger siblings). With the help of interpreters, it is usually possible 
for organizations to find para-professionals or professionals. Alongside agency staff, older women and youths could be recruited as volunteers (IASC, 2007). Members of the community can be trained to take over initiatives in due course (Cuninghame et al., 2001).

A high turnover of personnel should be expected. SC (2006a) claims that personnel will be leaving emergency response and small- scale initiatives (e.g. using volunteers) may not be sustainable over time. One solution to maintaining personnel is with rewards. Cuninghame et al (2001) suggests that organizations must be consistent with reward policies for ECD personnel and be agreed upon and reviewed regularly.

It is suggested that ECD personnel possess specific qualities to work with young children and families. Personnel should have a warm personality (Cuninghame et al., 2001). All children in the evaluation in Bangladesh mentioned that relief workers should be friendly, kind, and not discriminatory against or abuse children (SC UK \& UNICEF, 2006). Personnel should be able to openly communicate with children and adults. Especially with children, they must be reliable (i.e., punctual and fulfilling responsibilities) as it recreates a sense of trust and security (Plan, 2007a).

According to Cuninghame et al. (2001), personnel characteristics should be assessed through short interviews. Interviewees should be informed of child protection issues and organizations' approaches (e.g. inclusive practices) because the IFE Core Group (2006) points out that cultural expectations and personal experiences may present barriers to relief. These must be addressed early as staff attitudes influence the safety of emergency relief for both children and personnel. 
Once personnel are selected, it is recommended that short training sessions be run. Materials used in training should be collected in pre-emergency phases. Suggested priorities in training include importance of play, children's rights, strategies for working with groups of children (e.g. positive behaviour management, health and safety), and relative safety and risk factors. Cuninghame et al. (2001) suggest that the planned contents of ECD emergency kits and other relevant equipment be explained and understood by staff. If possible, the production and viewing of a video on key issues could be used with training modules or as advocacy tools (SC, 1999). It is suggested that personnel be advised that substantial learning comes with experience. They must also be informed that their perceptions on what is beneficial for children may not necessarily be shared by the local community. It must be ensured that all relevant staff understands their operational roles in the relief initiatives (Cuninghame et al., 2001).

Cuninghame et al., (2001) recommends that ECD personnel have particular knowledge for working with children that have experienced emergencies. They should be ready to support children's feelings and expressions and have a clear understanding of the local community's beliefs on development, distress, death, suffering, and coping strategies. It is suggested that staff be generally alert to feelings of distress and their manifestations in children and families and know how to take appropriate steps to support distressed children (Cuninghame et al., 2001).

\subsection{Material Resources}

The following section discusses material resources that have been recommended by guidelines and evaluations for emergency relief. 
Emergency kits are commonly provided by organizations in emergency relief. The content of kits is variable but usually includes books, toys and games. However, there have been difficulties with the appropriateness of kits including cost, longevity of resources, training required, and cultural appropriateness (Kamel, 2005).

Children in Bangladesh made recommendations about what should be included in relief distribution. One request by children was for the greater distribution of children's clothing (SC UK \& UNICEF, 2006); however, in response to the 2004 tsunami, communities in India preferred to have material to make their own clothing instead of piles of inappropriate clothing (BvLF, 2005). Also requested was the distribution of cots for babies (SC UK \& UNICEF, 2006).

Monetary distribution was also recommended. Families asked that money be given, instead of food, where quality food is available for purchasing at fair prices (SC UK \& UNICEF, 2006). As cited by BvLF (2005), the distribution of loans for microenterprise and relief should be considered as more sustainable than any form of welfare benefits. For children in extended care that run the risk of being abandoned or put in institutional care, even modest support may make a considerable difference to the capacity and willingness of families to continue providing care. Monetary provision was also recommended for families who are forced to leave their children to go to work to feed their families (SC UK \& UNICEF, 2006).

Families in Bangladesh requested daycare services for working mothers because the majority of child deaths occurred when parents left their children to go to work, to get food, or in the care of siblings (SC UK \& UNICEF, 2006). Tolfree (cited in BvLF, 
2005) suggests that providing daycare is beneficial because older children, often females, do not have access to education because they have to look after younger siblings.

\subsection{Advance Preparation}

The following section covers recommendations for emergency relief preparedness and planning before the onset of an emergency.

Cuninghame et al. (2001) suggest that emergency relief for young children be an integral part of agencies' and communities' pre-emergency planning (Cuninghame et al., 2001).

There must be organization/agency staff with sufficient prior knowledge and understanding of ECD issues in country/region for emergency relief planning. Planning includes thinking about issues that might arise before, during and after the emergency. Cuninghame et al. (2001) identifies two types of information gathering for preemergency planning. The first type includes information that can be acquired over a long period of time well before the emergency occurs. The second type includes information that may only be readily accessible right before the onset of an emergency. Most international and non-governmental agencies will have advance warning and be in a state of alert for civil and international conflicts and natural disasters.

Cuninghame et al. (2001) suggest that pre-emergency planning cover areas such as: staffing and management structures; local partners and community knowledge of early childhood development, care and education; government policy; and international agencies involved in relief. WHO (2003) also recommends that the health status of young children in regions of interest be covered. IFRC/ICRC (2005) advises that children's lifestyles be assessed. Questions to address this include: What are common 
daily routines? Are they changing, and if so, how? Are there child headed households? If so, why is this? What are the roles and responsibilities of children in the household and community? How many children go to school and what is the level of education. Cuninghame et al. (2001) suggest a plan be developed including ECD curricula, volunteer training, logistics, material kits, monitoring and evaluation plans. The components in pre-emergency planning must be regularly reviewed and updated with national staff.

In disaster prone areas children and families can be advised how to safeguard themselves (e.g. children can be taught to swim and communities taught first aid techniques for drowning children in flood prone regions) and their property. Children can be prepared for what might happen and how to get help (Plan, 2007c).

The most important preparedness factors identified in UNICEF (2005) evaluations were the availability of staff experienced in humanitarian response, on the ground presence, partnerships, and rapidly available in-country relief stocks.

Coordination with other relief agencies must be built into the pre-emergency plan for young children. It is recommended that agencies seek relevant emergency response from other key agencies, such as UNHCR, as early as possible. It is also recommended that agencies and organizations be aware of UNHCR support and expectations of participating donors (Cuninghame et al., 2001).

\subsection{Collaboration and Coordination}

Collaboration and Coordination discusses the collaboration and coordination of international and local actors in emergency response. 


\subsection{The Coordinating Role in Emergency Relief}

According to WHO (2003), the MoH should be the lead for in-country coordination of NGO and international agencies’ activities. A minimum package of services and health interventions, including training materials and guidelines to respond to local needs and strengthen health information systems, should be established by the $\mathrm{MoH}$.

In complex emergencies, due to the breakdown or absence of traditional authority and administrative structures, another coordinating or supportive agency may have to be identified. Globally, WHO (2003) has claimed the mandate to provide policy guidance to existing institutions, quality assurance, and standard setting for performance and implementation of health initiatives for children. The primary role of WHO is to apply this global mandate at the local level by supporting the MoH through technical assistance and fostering coordination among various agencies and health care providers on the ground. In circumstances where WHO may not be the most appropriate coordinating agency, identification of another institution is necessary.

SC UK (1999) suggests that UNHCR is the lead coordinating agency in crisis with logistical support of early operations by North Atlantic Treaty Organization (NATO). WHO is responsible for communicable disease surveillance in camps and in host family arrangements. UNICEF (2006) claims that in most emergency affected countries, UNICEF's in-country staff led initial responses and UNICEF national personnel were often in the front line of response. 


\subsection{Inter-Agency Coordination and Collaboration}

Lack of coordination and collaboration amongst relief actors affects all aspects of emergency relief (Cuninghame et al., 2001). Umbrella organizations (e.g. IASC) hope that their formation forges stronger links among other organizations thus providing a firm base for future shared work, cooperation and communication, especially during disasters (SC UK \& UNICEF, 2006).

INEE (2004) and UNICEF (2006) suggest an integrated approach in emergencies with partnerships for sanitation and hygiene, health and nutrition, protection, and early stimulation and learning. UNICEF (2005) suggests that actors participate in inter-agency exercises to regularly update risk and threat analysis and establish appropriate analytical and long-term information requirements.

According to IFRC/ICRC (2005) there are many ways of dividing up responsibilities in collaborative joint assessments. IFRC/ICRC claim that the repetition of assessments in the same region by different organizations is inefficient, frustrating and can have negative impacts on aid efforts. There are two possible scenarios for collaboration in assessments. First, agencies specializing in different sectors could divide tasks and responsibilities between them (e.g. one team focuses on water supplies and access to health care and another on schooling for displaced children). Also, agencies with similar interests can divide the area geographically (e.g. IFRC/ICRC and the World Food Programme (WFP) can divide the geographic area for food-security assessments).

Joint assessments are feasible under certain conditions. They are feasible when participating organizations share common values, operational principles and use the same or compatible assessment methods. They are not appropriate where assessments are 
mandate specific (e.g. IFRC/ ICRC protection work), organizational values and operating principles are not compatible, collaboration jeopardizes principles of neutrality and impartiality, and organizations and/or individuals are prejudiced (IFRC/ICRC, 2005).

Cuninghame et al. (2001) suggest that the basic requirement in pre-emergency planning and operational stages of emergencies is to coordinate resources between agencies. This can be done by sharing knowledge and materials and dividing specific responsibilities (e.g. area of work or geography).

When collaboration is lacking there is a lack of accountability and inability to sanction inappropriate action. Preparedness plans in high risk countries or regions are possible tools for overcoming potential problems. Plans at both the global and country levels include pre-identification of an appropriate and capable institutional leader, common standards and rules of engagement for major players, assessment and evaluation tools to measure success of interventions, and a commitment of financial, human and technical resources by partners (WHO, 2003; Cuninghame et al., 2001).

According to WHO (2003), poor coordination and a lack of leadership may be the biggest problems and leading causes of death in emergencies. Weaknesses caused by the former may hinder the introduction of essential response initiatives such as disease prevention and life-saving intervention.

\subsection{Local and International Coordination and Collaboration}

Cuninghame et al. (2001) suggest that emergency plans developed by donor agencies should ensure that their initiatives are complementary and have equal emphasis on local initiatives. If international donor agencies can support activities for young 
children outside of camps they are obliged to according to the SPHERE charter of humanitarian principles and the IFRC/ICRC code of conduct.

Local communities can be responsible for gathering information about child rearing practices and risks for children (IASC, 2007). For example in the 2001 Gujarat earthquake women were involved in identifying high-need households and directing aid to them.

Local groups could be formed to raise awareness about dangers (e.g. risks of abduction), monitor security, and organize and maintain hygiene in shelters. In Bangladesh when there was strong community organization and awareness, parents and caregivers noticed fewer incidents of child abduction (SC UK \& UNICEF, 2006).

It is recommended that organizations collaborate with smaller NGOs and private donors by spreading awareness through local resources. When interviewed in Bangladesh, children stressed the importance of information sharing and awareness about key issues using loud speakers, campaigns, and leaflet distribution (e.g. warning parents against the splitting of families during floods). Children also recommended that there be child-to-child methods for dissemination of health and safety issues. It was pointed out that community initiatives foster a spirit amongst neighbours to help each other (SC UK \& UNICEF, 2006, p19).

Rescue teams in emergencies could be made of local community members (SC UK \& UNICEF, 2006). IFRC/ICRC (2005) claims that in emergencies community members are the most active and comprise the biggest rescue teams; however they often go unrecognized in their efforts. 
Local media can also be used in emergencies. It is recommended that the same means of public service announcements regarding hurricane or flood warnings can be used for educational programming during emergencies (Sian Williams, personal communication, 2007). Recommendations for preventative action can also accompany warnings broadcasts (e.g. warnings against health risks in their immediate environments).

In the response evaluation for the 2004 tsunami, it was found that partnerships with local NGOs worked best where there were pre-existing relationships with trusted, well-established organizations and were less successful where UNICEF worked with smaller and newer NGOs (essentially contractors) (UNICEF, 2006).

\subsection{Assessments, Monitoring and Evaluation}

The following section outlines criteria in guidelines reviewed for conducting assessments, monitoring and evaluating relief initiatives.

\subsection{Assessments}

WHO (2003) claims that emergency interventions are determined by individual organizations or donor parties and not by people in need.

It is suggested that within the first week a simple data collection plan be developed for one month covering key data gaps required for continued emergency response. Ideally the plan should also reflect key data collection activities by other organizations (SC UK \& UNICEF, 2006).

Initial assessments will rely on information about communities during preemergency planning. Cuninghame et al. (2001) recommend that assessments in emergencies should be made as soon as possible as it is secure to do so. A rapid initial assessment must be conducted to identify priority humanitarian relief for children 
(UNICEF, 2005). It should estimate the number and ages of children under eight years old, the number of pregnant women and women with newborns. Disease surveillance systems must be rapidly established particularly for diseases known to cause outbreaks with high mortality (e.g. measles and diarrhea) (WHO, 2003). Other questions that INEE (2004) recommend for initial assessments include: Where and when should early childhood activities take place? What age groups are targeted? Where should safe spaces be? Is there a need for multiple shifts? Who will implement the activities and what training, materials and supplies are needed?

It is recommended that assessments be continuous and consult as many children as possible according to sex, age, and background, as needs vary and change throughout emergency phases (SC UK \& UNICEF, 2006).

CCF (cited in BvLF, 2005) begins their rapid assessment by reviewing existing data and identifying gaps to guide the collection of new data. The preferred assessment strategy is to cooperate with other agencies in conducting large- scale assessments with each partner covering particular geographic regions. Work is guided by strategic informants who are from the local area and familiar with the language, situation and customs. The informants provide advice on the cultural protocols for entrance into villages, identifying local resources and protection issues, and handling ethical issues associated with assessments. In the process CCF probes informants' views of childhood and children and learns about local resources that could support children in the current context. CCF staff visits villages typically to meet elders, teachers and other important local figures to obtain a broad overview of children's situations. These meetings are followed by group discussions. They use visual methods for children and non-literate 
adults. CCF's strategy is useful in tailoring the assessment to political, historical, economic and social contexts of emergency affected populations.

The IFE Core Group (2006) suggests factors for emergency response for young children that can be assessed qualitatively and quantitatively. Qualitative methods can be used to assess: availability of appropriate food; the health environment; the capacity of potential support givers; and cultural practices. Quantitative methods could be used to assess demographic information and resources.

After initial assessments, WHO (2003) suggests there be a meeting with participating agencies’ members to prioritize health and nutrition interventions. Barriers for health provisions should also be identified in order to provide appropriate and effective health care interventions. It is also recommended that systems be implemented to begin monitoring activities and referrals to co-providers (Cuninghame et al., 2001).

\subsection{Monitoring and Evaluation}

It is suggested that time and personnel always be allocated for up to date information gathering (Cuninghame et al., 2001). It is vital to ensure that there is constant updating of information and monitoring of emergency responses. SC UK (1999) suggests personnel and agencies document as far as possible the flow of relevant relief items such as BMS and infant feeding bottles. A valid and reliable system for monitoring is recommended to regularly report and publicize the needs of children and evaluate the impact of relief. Agencies should also develop an integrated monitoring and evaluation plan to support management of the operational response with key indicators on implementation and output (SC UK \& UNICEF, 2006). 
Key aspects of monitoring include: children's activities; toys and materials (quality, quantity, and appropriateness); the number and condition of severely affected children receiving extra support; training; volunteer staff; organization relationship with caregivers and the wider community; and the scope and the direction of emergency response for children as a whole. Materials must be regularly checked, replaced or modified where necessary (Cuninghame et al., 2001).

According to SC (2005) there must be a comprehensive, timely, and reliable monitoring system to ensure compliance at the field level. The comprehensive system should be confidential and establish consistent standards and methods for identifying, documenting, and verifying child rights violations. This information can be used to mobilize opinion, inform policy development and resource allocation, and guide program interventions. The system should be based on the three components of legal principles including international law, accountability to the people including children, and transparency. The system should detect early warning signals, promote early action, and deny impunity for those who commit crimes against children. States should be held accountable for their actions but also their failure to take action.

It is suggested that once the emergency relief is over the capacity building and technical support requirements among operational partners be evaluated and addressed by a coordinating body.

Monitoring and evaluation are powerful where they are set up with the involvement of local communities to determine the effectiveness of emergency response. Among participants providing humanitarian relief, this information leads to reflection and modification where necessary (Cuninghame et al., 2001). 


\subsection{Discussion}

The well-being of children in emergencies is largely dependent on humanitarian relief. Appropriate and timely responses could ultimately determine how well children cope with and survive when emergencies occur. The following discussion addresses strengths, weaknesses and gaps found in the review of selected documents from a child rights moral framework according to the UNCRC. Recommendations for emergency guidelines are also included.

\subsection{Strengths}

There are several strengths observed in the documents reviewed. The first strength is the focus on young children in emergency relief. Second, with the recognition of ECD in emergency guidelines, awareness is spread to governments and organizations that have not invested in ECD in the past. Awareness is the first step to change. With time, effort, increased awareness and international pressure it is more likely that there will be increased investment in the early years by governments and the international community.

The guidelines also identify the basic elements that can be applied universally which include the establishment of safe space for children's play, the involvement of family and community in ECD initiatives, infant mother support, and care for caregivers. Although details and methods of implementation are context specific, these concepts are universally relevant and applicable.

Another strength identified in the document review is the identification of the need for collaboration and coordination in emergency relief. To date there have been significant efforts in the collaboration of agencies in emergency response, such as with 
INEE in 2001. INEE has grown to include over 500 non-governmental organizations, educational and research institutions, bi-lateral and multi-national agencies (Kamel, 2005). There are many advantages associated with this collaboration; however, there is still much more work needed.

Another significant strength is the strong focus on evaluation from previous emergency relief efforts. Although emergency relief is largely context dependent, the communication of experience in different contexts has the potential to reduce future error, inform preparation, and increase emergency response effectiveness.

A significant development in the guidelines is the inclusion of children and families in describing the impact of emergencies. These first hand accounts of personal experiences identify realities that are not obvious to outsiders. They put a human face on the statistical data to represent a more powerful image of what children and families experience in emergencies.

\subsection{Weaknesses and Gaps}

\section{a) Consistency}

There are several inconsistencies identified amongst agency guidelines including concepts, definitions and mandate and actual response. Inconsistencies can potentially create confusion in the field and reduce the effectiveness of emergency response.

First, organizations need to commonly identify and define a term to describe emergency response for young children. Terms used in the guidelines include 'early childhood education and care' and 'early childhood development programming'. Each of these terms can be interpreted differently in different contexts. These terms also do not accurately reflect what the majority of guidelines focus on in their recommendations, the 
meeting of children's fundamental needs (e.g. health and safety). Actors must commonly identify one term or differentiate between terms to begin creating a consistent understanding about support for children in emergencies.

Second, there is an important differentiation that must be acknowledged in emergency response that is not identified in any of the documents examined. There are two types of emergency disasters (Sian Williams, personal communication, 2007). The first type is an isolated event (e.g. Asian tsunami triggered by the massive earthquake off the coast of Sumatra) and the second type is the constant threat of disaster (e.g. seasonal hurricane and flood threats in regions of Jamaica). Both types of natural events are classified as disasters that may require international assistance and have similarities in preparation and relief needs, but there are also specific differences.

One of the main differences in the two types of emergencies involves preemergency planning and preparedness. In regions of constant threat IGOs, INGOs, NGOs, and local actors can work with communities for preparation and readiness. According to Sian Williams (personal communication, 2007), preparation in prone regions should be an integrated and normal part of annual household planning. Preparation and readiness reflect a capacity building approach to emergency relief, potentially enabling and empowering people. People have more opportunity to be active instead of reactionary.

One weakness identified in the review of documents is the inconsistency in the definitions of key terms. For example, in the evaluation conducted by SC UK (1999) it is identified that agency criteria for supplementary food distribution varied across organizations. The age criteria across agencies were 0-3, 6-59 months, 6-36 months, 4-8 
months and in some cases all infants. The evaluation also identified that the definition of complementary foods varied across providers. The UNHCR defined 'complementary foods' as foods additional to the basic commodities supplied by WFP for the food ration. Nutritionists defined 'complementary foods' as foods introduced into infants' diet to complement breast milk at approximately six months of age. The same evaluation claims discrepancies as to what constituted a 'mother baby tent'.

Other discrepancies were found amongst recommendations for ECD initiatives. For safe space provisions IASC (2007) guidelines suggest establishing spaces exclusive for ECD initiatives and SC UK \& UNICEF (2006) suggest that space does not have to be exclusive but must be available for at least one hour per day. Similarly, in regards to activities Cuninghame et al. (2001) suggest that toys should not be gender specific and the IASC (2007) guidelines suggest that they should be.

Consistency in the definitions of major terms is essential. Variations in provisions according to the context can be accommodated, but if key terms and concepts are interpreted differently by actors there is likely to be duplication or neglect of particular kinds of supports.

Another weakness in the guidelines involves the ambiguity of concepts, specifically the UNCRC 'best interests of the child' and the use of 'common sense' in emergency relief.

According to the UNCRC, the framework adopted by many donor agencies in emergency relief, the 'best interests' of the child is identified as a primary consideration in all actions concerning children (UN, 1989). It is difficult to determine what 'best interests' are especially within the complexity of emergencies and when children are not 
involved in the decision making process. However, the determination of what constitutes the 'best interests"' of the child is very significant as it guides decisions that determine children's futures. This discussion is especially relevant with separated children in emergencies. As Kim Snow (2006) writes in her article Vulnerable Citizens: The Oppression of Children in Care, "fundamental to the concept of best interests is that children are not competent and therefore incapable of being full-fledged right bearers” (p.96). Furthermore, she questions "Who makes the decision? What happens if what one person believes is in the child's best interest is believed by another to actually be harmful to the child? Who has a say and how is the decision made" (p.95). The result of this ambiguity is evident in the example in Posoltega, Nicaragua after Hurricane Mitch in 1998. As a result of the hurricane, as a gesture of good will by the mayor, unaccompanied children were taken to an orphanage in the capital. Although the majority of children were orphans they had close relatives that were able to care for them but were unable to be united as a result of the relocation (SC Sweden, n.d (a)).

One way to reduce the ambiguity of the 'best interests' concept is to listen and involve children and communities in decisions affecting them. Children are commonly ignored in decision-making. However, they often know their environment best and are able to make well informed decisions regarding their own well-being and that of the entire community including the very young and very old.

In many of the guidelines the use of 'common sense' and 'logic' is recommended when organizing emergency response for young children. This is potentially problematic. Common sense is largely determined by experience within particular cultures and as a result is highly variable. So called 'common sense' may be impractical 
or not culturally appropriate within the complexities of emergency response and cannot be universally applied.

What should be emphasized, as mentioned by Cuninghame et al. (2001), is the promotion of communication and collaboration to develop and organize response initiatives. With accumulated experience and local/community knowledge, dialogue is the best way to determine how emergency relief would be most effective and safer for children.

There have also been inconsistencies identified between mandated responsibilities and action on the ground. UNICEF is supposed to be responsible for the monitoring of breast milk substitutes. However, SC UK (1999) found breast milk substitutes not generically labeled or in local languages. Also, in Bangladesh the size of BMS packets were insufficient to meet children's needs. One month’s supply was distributed for three months use (SC UK \& UNICEF, 2006). More effective monitoring, effort and accountability could decrease these gaps.

\section{b) Practicality}

Another shortcoming involves the practicality of guidelines. It is recommended by the IFE Core Group (2006) that in emergencies families with infants using BMS have infants weighed and home visits at least twice a month by trained personnel. But WHO (2003) claims that there is often limited staffing and staffing capacity, especially skilled health workers in emergencies. The recommendation of having infant health specialists and the resources for the recommended infant monitoring does not appear practical. Also, in Kosovo personnel were to support the re-lactation of mothers but it was also claimed that re-lactation was not practical as women were discouraged, stressed and did 
not want to breastfeed. As a result more research was recommended for the practicalities of re-lactation (WHO, 2003). Staff working in Kosovo also expressed that there were too many guidelines and not enough time, therefore their familiarity with them was slim (SC UK, 1999).

Recommendations should be practical and response plans should be determined by comparisons between needs assessments and resources. A suggestion for determining the practicality of guidelines is to review evaluations from other relief projects in the region or the same type of emergency while developing response plans. The comparison of resources and needs should be consistent throughout emergency relief. Monitoring and modification can help close the gap between plans and realities if there is a discrepancy.

c) Protection

Although the protection of children is emphasized in organizations' approach to emergencies, there are areas of risk neglected. It is mentioned in some guidelines, but not adequately emphasized, that personnel providing emergency relief pose a risk to children. Children and families in Bangladesh said that there must be greater understanding of the risk that adults in positions of power and trust can abuse children during emergency situations. Children mentioned they needed protection from shelter organizers, rescue workers, relief distributors, and members of the public. They also criticized agency personnel for failing to protect them. The frequent abuse of boys from men in power was also expressed. Children also described how alcoholics and drug addicts were put in the same shelters as families (SC UK \&UNICEF, 2006). Children face significant risk for abuse and exploitation by other displaced individuals in shelters. 
There must be greater responsibility and accountability for the protection of children. It was recommended that governments or donors who indirectly hire or contract personnel must take greater responsibility for limiting potential opportunities for abuse. Community policing was also recommended as a deterrent (SC UK \& UNICEF, 2006). Effective and vigilant monitoring of relief operations promotes the protection of children. Collaboration amongst agencies would be beneficial in reducing these risks because a collective structure in shelters or regions would increase accountability and resources available for security therefore increasing the protection of children.

\section{d) Groups Missed in Relief}

In emergency relief there are several groups of people that are consistently mentioned in evaluations as missed in emergency support.

A significant gap in provision involves the 'missing' in emergency relief of marginalized and discriminated populations. The targeting of marginalized and discriminated populations, except for children with disabilities, is only briefly mentioned in guidelines. Recommendations for targeting these populations in emergency relief are absent in guidelines. Groups that are marginalized, discriminated against, and vulnerable are context dependent; however there are populations that are discriminated against almost universally including street children, unaccompanied and orphaned children and children with disabilities. In guidelines these children are identified as requiring special efforts; however these groups have been found denied food and shelter in emergency situations. In the SC UK and UNICEF (2006) evaluation children expressed that children unaccompanied by adults were 'invisible’ to relief personnel and adults. 
Accompanying this invisibility, children were 'missed' with methods of provision distribution. In Bangladesh household models were used for food provision, but this method excludes children unaccompanied or outside of the family unit. Room-to-room methods were suggested but this method was expressed by NGOs to be too time consuming and not cost effective (SC UK \& UNICEF, 2006).

Similarly, although women and children are consistently identified as neglected and needing attention with humanitarian aid, the ICRC 2006 World Disaster Report identifies that they are still being neglected in emergency response (ICRC, 2006).

There are many factors that contribute to the 'missing' of children by humanitarian aid; however this gap in provision may be intentional. This intentional discrimination is demonstrated in the Balkans where Romas who were culturally discriminated against were also overlooked in provisional distribution. People that are 'invisible’ are often systematically made invisible. Paulo Freire (1970) claims that society systematically gives privilege to certain groups of people in society and oppresses others. This is also evident in humanitarian relief. As governments and organizations with particular agendas determine the distribution and form of humanitarian relief, some groups of people have privilege and others are marginalized. Guidelines in emergency relief need to draw attention to people who may be systematically missed in emergency relief.

Tending to marginalized populations is complex; however if the main goal of humanitarian relief is to help people cope and survive and help people most in need, significant efforts must be made to target marginalized and discriminated populations. One way to mediate this gap in provision is to identify marginalized and discriminated 
against populations in pre-emergency planning and initial assessments in the country or region affected. Initiatives must be specifically designed to provide assistance to these populations.

\section{e) Displaced People Outside of Camps}

Within the guidelines there should be more attention to people outside of camps and shelters. In guidelines reviewed recommendations for accessing refugee or displaced children living with host families are lacking. Similar to marginalized populations specific efforts must be made by organizations to support these groups. Initial assessments must focus on identifying these groups and a plan should be developed to provide support during emergency relief.

\section{f) Communication}

In the guidelines reviewed effective mechanisms for communicating with children in emergencies have been neglected. As Richman (2000) claims in Communicating with Children, communication is key to support.

According to Emily Vargas-Barón and Hernando Bernal Alarcón, (2005), effective communication with children involves: paying attention to the other person; being a good listener; being aware of non-verbal communication; using simple language; using open questions; and making sure there is mutual understanding. Aid agency personnel must be aware of their non-verbal communication when helping children and families cope with emergency situations. There must be sensitivity to and awareness of cultural variability in communication, including tone of voice, facial expression, encouraging noises, nods and smiles, and height difference (Richman, 2000). Although eye contact is very culturally dependent, a certain degree of contact is usually helpful. It 
is best to allow time for children to gain confidence and not look at them too much at first.

It is important that personnel are compassionate, calm and receptive to children and families at all times. This element in interaction is important for reducing anxiety and supporting people in times of distress.

Promoting emotional interaction between caregivers and infants in emergencies and for the general healthy development of children is also neglected in guidelines reviewed. All of the guidelines reviewed discuss the importance of breastfeeding for holistic development; however the nurturing element of child care is generally neglected. The elements of mother-child bonding (affection, nurturance and communication) in breastfeeding are identified as benefits but often secondary to the health benefits of breastfeeding. These emotional elements are just as important for the healthy development of young children. Nurturing and affection are necessary for the healthy physical, cognitive and social development of children. In addition to healthy feeding practices, parents must be supported and informed of the necessity of parent-child emotional interaction.

Another form of communication neglected is that with governments, other organizations, and the media. Aside from collaborative efforts, it is important for organizations to communicate with other actors in emergency response to coordinate, and increase the effectiveness of response initiatives (e.g. reduce redundancy and gaps in response). Publicity can increase international involvement (e.g. monetary contributions) and spread awareness of emergency issues pertaining to children. 


\section{g) Development and Relief}

There is a relationship between humanitarian relief and development. The relationship is not explicitly identified in guidelines by primary relief agencies but is suggested in different ways. One example in guidelines of the relationship is the consideration of the longevity and sustainability of ECD initiatives in emergency relief. The relationship is mentioned by smaller relief organizations such as Plan who asserts that they are a development agency that works in emergencies as part of their development strategy (Plan, 2006). Kamel (2005) states that there is a growing consensus that crises intervention should be considered a part of the business of development rather than as an ad hoc response. She also describes the difficulties arising out of this relationship including the splitting of policy, operational responsibility, and funding mechanisms between development programmes and humanitarian relief activities by governments and humanitarian agencies.

The changing of educational systems has been mentioned in relief guidelines and evaluations as an integral part of the introduction of early childhood education and care programming in emergencies, especially where ECD initiatives did not previously exist. Cuninghame et al. (2001) suggests that emergencies provide the opportunity to introduce ECD initiatives where it was non-existent before.

Development as part of international organizations’ approach in humanitarian relief should be actively taken into consideration when planning and implementing emergency response. Collaboration, amongst agencies, different units within the same agency, and local and national governments, focusing on development and on relief must be encouraged whenever possible. These collaborative efforts will increase the 
effectiveness and longevity of initiatives, targeting initiatives not only at relief but also at recovery and development.

\section{h) Coordination}

Coordination within agencies has also been identified as a shortcoming in emergency relief. With one agency, nail polish colours were used to code different types of formula for distribution but distributors thought they were flavours and distributed them as equals (SC UK, 1999). Provision of materials and services gets complicated as a result of the logistics in response. When the lack of distribution of appropriate food was addressed in post-emergency reassessments an NGO said that there was no food for young children because the content of packages was decided at the donor level. But the donor level reported that the content of packages distributed was based on the information they received from a NGO’s needs assessments (SC UK \& UNICEF, 2006).

There must be greater mechanisms for accountability and better communication within organizations and agencies. Also, if organizations work together for assessments and distribution and create common outlines for response, unnecessary confusion and gaps can potentially be avoided.

\section{i) Evaluations}

The importance and multiple uses of evaluations are absent in guidelines. Evaluations are very useful if they are used. Although evaluations have been perceived as a strain for people on the ground on top of the programming, they are essential for improving response in emergencies (Williams, 2007). Evaluations can have many functions but only their potential for reflection and modification are mentioned in guidelines. Evaluations should be widely distributed to local and international 
organizations. They identify risks, emergency relief weaknesses, failures, successes, and more. One function of evaluations is to inform preparedness initiatives in disaster prone regions. They can be used to identify prevalence and causes of regional illnesses and death and in turn be used for preventative action (e.g. raising beds a foot off the floor to avoid sand insects spreading disease).

\section{j) Resilience-Based and Capacity Building Approach}

Resilience-based approaches and capacity building support in emergency relief are briefly mentioned in guidelines but need a sharper focus. SC claims that their initiatives build on resilience and have a community-based approach (SC, 2005) which encourage self-help, builds on local culture, realities and perception of child development (SC Sweden, n.d (c)). However, it has been observed that in many of the guidelines, including that of SC, international humanitarian relief is provided with an interventionist approach. This is evident in the consistent use of terminology such as 'intervention', 'counselling', 'trauma' and 'treatment' to refer to response initiatives in guidelines. This “well-validated” (Wessels \& Monteiro 2004, p.328, cited by Kamel, 2005) medical model is a Western method of support but does not suggest a community, culture, nor resilience based approach.

In the interventionist approach there is an emphasis on assessing needs, hazards and vulnerabilities in the affected population. At the expense of this approach are the strengths, skills and resources possessed by the affected community. Emergency response must focus on resilience instead of undermining it. According to IFRC/ICRC (2005), resilience is "the capacity to mitigate, prepare for, respond to and recover from 
the impact” of an emergency, but often response is top-down and promotes dependency but the affected population.

There are many benefits associated with the resilience-based approach that are widely known. In the resilience approach, when relief builds on peoples' capacities, people can share their capital and help each other. Agencies can build on the strengths of children and families instead of treating them as passive and needy victims. Building on the capacities of families and children is a more sustainable approach to humanitarian relief.

The role of humanitarian aid becomes that of supporting indigenous capacity and working with communities to support their efforts and capacities. Vargas-Barón and Bernal-Alarcón (2005) write that at the very least, relief should not undermine local capacity. Emergency response must support parents and community members in finding their own ways to meet their needs and their children's needs to regain a sense of control in their own and their children's lives.

\section{k) Local Involvement}

Another weakness in the guidelines is that all of them advocate for the involvement of local communities but there were limited suggestions about how this could be achieved. CCF is one organization where the use of 'specialized informants' and their role in assessments were described. Furthermore, 'consulting' does not mean ‘involving' or 'collaborating with’ communities in emergencies. Working with communities must be the approach of all humanitarian relief. Working with communities may be the intention of organizations, however, 'consulting' and the use of 'specialized informants' does not imply collaborative effort and action. 
In the Local and International Collaboration section of the review, the majority of suggestions mentioned were from evaluations in which affected populations suggested how they could be a part of the relief process. Community involvement is discussed in the Recruiting and Training of Personnel; however more effort needs to be focused on ways to involve communities in the relief process such as with programme development, therefore fostering a resilience and capacity building approach to relief. One way is to look at evaluations and identify the ways that communities offer their capital (e.g. skills) such as musicians and artists. Another suggestion is to assess peoples' capital in preemergency situations or initial assessments and inform people of how they can utilize their skills to protect themselves and others in the community in emergencies. This information can also be used by organizations to identify people in the community that can be used in emergency response.

Also, the top-down approach to humanitarian relief is not always welcomed in communities due to previous response shortcomings. In From Bullets to Blackboards: Education for Peace in Latin America and Asia (Vargas-Barón \& Bernal-Alarcón, 2005), communities in post-crisis Indonesia said that they had lost trust in INGOs and NGOs because they felt that organizations had been given large amounts of money for emergency aid and the people most in need were neglected.

Although community involvement is important in relief, it must be recognized that there may be tensions in the priorities of local actors and the priorities of international actors. Limitations in community involvement can be assessed in advance or identified through monitoring and evaluations. Limitations do not suggest that community involvement in relief should be avoided. When tensions do arise they should 
be addressed appropriately as the role of international actors in emergency response is to support the affected population.

When there is a high level of community involvement there is a level of ownership and responsibility, especially with young children. Involvement in itself is capacitating. Vargas-Barón and Bernal- Alarcón (2005) also suggest that involvement is part of the healing process after crisis. As part of healing, it is important for community members and victims to be in control and make well-informed decisions about the education and well-being of their young, as other parts of their lives in emergencies (e.g. food and shelter) could be totally dependent on others.

It is widely known that there are many violations of children's rights in emergency situations; however, what is not acknowledged is the issue of child participation in decision-making. Children in Bangladesh claimed that despite their initiative to participate in emergency relief they were undervalued by adults including response personnel and elders in the community. For example, older children asserted that they could function as child protectors and that they had the potential capacities to cope with disasters, but they were eventually ineffective as adults undervalued them (SC UK \& UNICEF, 2006). Also, as mentioned previously in connection with the determination of the 'best interests' for separated children, children are not involved in the decision-making processes that affect them. Snow (2006) writes that the UNCRC claims that children have participatory rights, however "having the right to participate is not the same as having a right to decide (p.96)”.

Children must be involved in decisions that affect them and their input must be valued. As stated above, children often make decisions for the well-being of the entire 
community and they have knowledge and see things from a different perspective than adults. They can help make decisions for their own well-being and for younger children. This is consistent with the use of the Child Rights Framework.

\section{l) Context Dependency}

The majority of guidelines also neglect to make recommendations and emphasize the importance of using local resources in ECD initiatives. The large majority of examples of activities are Western based suggesting the use of manufactured tools such as hoola hoops and plastic tools. As a result of the ethnocentricity of some recommendations, specific items and activities have been left out of the document review and universal recommendations were included.

Vargas-Barón and Bernal Alarcón (2005) give examples of post-emergency activities in Indonesia that use local resources for children aged two to six years. Program tutors use seeds and stones for mathematical operations and games. They also use wood, leaves, sand and water to learn about the environment. Traditional musical instruments are used to entertain and promote musical development. And hand puppets are used to tell traditional stories and folklore tales. Local resources are not only practical but promote the continuity of activities outside of emergency response initiatives and post-emergency.

In the guidelines reviewed, the recommendations for emergency response do not emphasize enough that plans and programming should be contextually and culturally determined. There are many recommendations in guidelines that must be culturally assessed for appropriateness. For example, in regard to children's manifestation of distress, IASC (2007) recommends identifying harmful responses to child stress such as 
beating, abandonment, and stigmatization and suggesting healthy alternative responses

and coping strategies to parents. Methods of acceptable disciplining and coping practices are culturally determined. Who would determine the alternative responses used, and how? These 'interventionist' approaches run the risk of cultural clashes therefore caution must be taken and culturally acceptable methods assessed. When clashes do occur, once again, confrontation should be avoided as the primary role of emergency relief is to provide support and not challenge systems unless children's rights according to the UNCRC are being violated.

This contextual dependency is also a contributing factor to the recommendation against the use of emergency kits in emergency relief. As Sian Williams (personal communication, 2007) working with UNICEF in Jamaica said, it does not make sense to have an emergency kit in the closet that has better resources than local early childhood initiatives use on a daily basis.

Elements of emergency relief, and generally all provisions in emergency response, are contextually dependent and should be culturally determined.

\subsection{Concluding Remarks and Recommendations}

Whether due to global climate changes or political conflicts, emergency situations disrupt the security and stability of children's daily lives. The failure to respond to children's needs and protect them from risks in emergencies results in personal tragedy and long-term social costs. If response is not appropriate to children's developmental needs, the consequences of emergencies can lead to a cascade of events that will forever leave children and families victimized. 
The current review has discussed the elements of emergency response in the prepatory, operational and follow-up phases of loud emergencies, outlining essential components in emergency relief for the restoration of stability and security in children's lives. Within the scope of the review, suggestions to reduce the gaps and weaknesses in emergency response for young children have been made. The first recommendation is for the identification and clarification of ambiguous and unclear concepts. Concepts used to guide emergency response must be clearly defined for a common understanding and consistent use amongst actors. Next, there must be greater monitoring of response initiatives in the operational phase of response to make sure that the affected population and children's needs are adequately met. Monitoring should include the consistent comparison of resources and people's needs and whether children's rights are being violated (e.g. sexual abuses). There must be greater effort to target the unique needs of discriminated against and marginalized populations; one solution is develop a specific response plan for these populations. Resources should also be designated for the affected populations' needs outside of camps. The must be greater awareness and efforts for effective communication with the affected population, government, other response actors and the media. The interconnectedness of development and relief should be identified at the onset of international response and planning as response initiatives are targeted not only at immediate relief but longer-term recovery. Another recommendation is that a resilience-based and capacity building approach must be used by organizations when providing emergency relief. International actors must support and build on communities' strengths and resilience so that people are active in their own, their families, and their community's recovery. Support must focus on children's abilities and not on their 
deficits. Lastly, it must be emphasized that response initiatives must be contextually developed. Local resources should be used in emergency response initiatives as they are more practical and promote the continuity of ECD initiatives. Children' lives are also context specific; therefore to adequately restore ‘normalcy’ in children’s lives, emergency response must match their specific needs, cultural traditions and norms. To conclude, there are three recommendations that are based on themes repeatedly addressed in the above review. The concluding recommendations are also essential in creating better outcomes and reducing the negative consequences of emergencies.

The importance of pre-emergency planning and preparedness is not emphasized enough in the reviewed guidelines. Advance preparation gives people the ability to be active and not passive victims of crises. Pre-emergency planning gives organizations and people the ability to prepare, prevent, reduce and alleviate the negative consequences of emergencies. Awareness and simple actions can determine resilience and survival and protect people from the primary and secondary consequences of emergencies. This preventative approach is widely applicable to all areas of response from health and safety to education and awareness. As identified in SC's child protection focus in emergency response, the best protection is in preventative measures, including strengthening individuals and communities in their abilities to protect themselves (cited in BvLF, 2005).

As suggested by many organizations and in several evaluations, the second recommendation is for collaborative efforts in emergency relief. There has been significant progress to date in establishing strategies and mechanisms for more effective 
collaboration; however there is much work still needed as there are still significant gaps in provision on the ground as a result of the lack of coordination.

Kamel (2005) claims that co-ordination efforts are often confused because the roles of different agencies are not always clear, complimentary or mutually understood leading to 'mandate clashes'. One coordinating organization must be established or a collective agency with representatives from various organizations/agencies must be formed to perform the coordinating role to alleviate confusion and create consistency in the field. Also, as suggested by Cuninghame et al. (2001) and WHO (2003), joint agreements and preparedness plans should be developed for emergency response outlining leading roles to reduce confusion in the field because, as mentioned above in the Coordinating Role in Emergency Relief, UNICEF (2006) claims they have a leading role in the field but WHO (2003) claims that there is a lack of leadership in the field.

Collaboration is plausible and practical as the majority of international agencies' approaches and goals of humanitarian relief are the same. Organizations even identify the same areas (i.e., hygiene, sanitation, health, nutrition, and education) for potential coordination and agree that collaboration and coordination is needed. The benefits of collaboration are far reaching. Most significantly collaboration will increase the effectiveness of response and use of available resources, therefore better meeting people's needs. Ultimately with collaboration, negative consequences of emergencies will be reduced and lives will be saved.

The last recommendation from the review is to include children in planning and implementing emergency responses. A good model for initiating this action is the childto-child approach. The approach has been used to help children in war, disaster and 
conflict. The child-to-child approach used by the Child-to-Child Trust UK (cited in BvLF, 2005) is a rights based approach to children’s participation in promoting health and sustainable community development. It is an educational approach that links learning with action.

The approach encourages and enables children and young people to promote the holistic development of health and well-being of themselves, younger children, their families and communities. Using a sequence of linked activities or steps, children think about health issues affecting them and their communities, they make decisions, develop their life skills, and take action to promote health in their communities. In this approach children frequently initiate, including organizing and implementing, activities and adults play a supportive role. Children create toys for younger children and are involved in encouraging parents to stimulate infants and young children. In an Afghan camp in Pakistan, one initiative involved simply finding out what makes other children smile and from that activities were created (cited in BvLF, 2005). Children as young as four and five have been involved and encouraged to share ideas and develop useful activities for themselves and the community.

In the child-to-child approach, children can assist in the provision of basic needs while playing a positive role and building their self-esteem and confidence. The child-tochild approach values the capacities of children while giving them the opportunity to think, make decisions, and take action. 


\subsection{References}

Bernard van Leer Foundation (2005). Responses to young children in postemergency situations. Early Childhood Matters, 104.

Castelle, K. (1990). Children have rights too: A Primer on the U.N Convention on the Rights of the Child. Ontario: Defense for Children International-Canada (Anglophone).

Christian Children’s Fund (2007). Emergencies. Retrieved June 25, 2007 from http://www.christianchildrensfund.org/emergency/.

Christian Children’s Fund (n.d). Christian Children's Fund in Brief: Emergency Programs. Virginia: Christian Children’s Fund.

Cuninghame, C., Hyder, T., and Kesler, D. (2001). ECD Guidelines for Emergencies: The Balkans. Save the Children Alliance.

Driskell, D., Bannerjee, K. and Chawla, L. (2001). Rhetoric, reality and resilience: overcoming obstacles to young people’s participation in development. Environment and Urbanization, 13(1).

Fine, S. (Director and Writer) and Nix, A. (Director and Writer) (2007). War Dance (Documentary). USA: Fine Films

Freire, Paulo (1970). Pedagogy of the Oppressed. The Continuum International New York: Publishing Group Incorporated.

Gall, J.P., Gall, M.D., and Borg, W.R. (2004). Applying Educational Research: A Practical Guide $5^{\text {th }}$ Edition, Boston: Allyn and Bacon. 
IFE Core Group (2006). Infant and Young Child Feeding in Emergencies:

Operational guidance for emergency relief staff and programme managers. Oxford: IFE Core Group.

INEE (2004). Early Childhood Development. In Minimum Standards for Education in Emergencies, Chronic Crisis and Early Reconstruction (INEE Minimum Standards)(Chapter 13). Retrieved February 15, 2007 from http://www.ineesite.org/.

IASC (2007). Facilitate support for young children (0-8) and their care-givers. In IASC Guidelines on mental and psychosocial support in emergency settings (Action Sheet 5.4). Geneva: Inter-Agency Standing Committee.

IFRC/ICRC(1995). The Code of Conduct for the International Red Cross and Red Crescent Movement and NGOs in Disaster Relief. Retrieved July 4, 2007 from http://www.icrc.org/web/eng/siteeng0.nsf/htmlall/57jmnb?opendocument\#a2.

IFRC/ICRC (2005). Guidelines for Emergency Assessment. Switzerland: International Federation of Red Cross and Red Crescent Societies.

IFRC (2005). World Disasters Report 2005 Summaries. Retrieved July 15, 2007 from www.ifrc.org

Kamel, H. (2005). Early Childhood Education and Care in Emergency Situations. (Commissioned Study EFA Monitoring Report 2007). UNESCO.

Pigozzi, M (1999). Education in Emergencies and for reconstruction: a developmental approach. New York: UNICEF.

Plan (2006). Tsunami 18 Months After. Bangkok: Plan International. 
Plan (2007a). Effective Disaster Relief for the Most Vulnerable. Retrieved June15, 2007 from http://www.plan-international.org/action/disasters/disasterrelief.

Plan (2007b). Children and Recovery. Retrieved June 15, 2007 from http://www.planinternational.org/action/disasters/involving.

Plan (2007c). Preparation can make all the difference when disaster strikes.

Retrieved June 15, 2007 from http://www.planinternational.org/action/disasters/preparation.

Plan (2007d). How deeply do disasters affect children? Retrieved June 15, 2007 from http://www.plan-international.org/action/disasters/effects/

Richman, Naomi (2000). Communicating with Children: Helping Children in Distress. UK: Save the Children .

Save the Children (1999). Meeting the nutritional needs of infants during emergencies: recent experiences and dilemmas. UK: Save the children.

Save the Children (2005). Protecting children in emergencies: Escalating threats to children must be addressed. Policy Brief, 1 (1).

Save the Children (2006a). Rewrite the Future: Education for children in conflictaffected countries. UK: Save the Children.

Save the Children (2006b). Together we play and learn. Save the Children: UK. Save the Children and UNICEF (2006). "Watermarks" Child Protection During Floods in Bangladesh. Save the Children: UK.

Save the Children (n.d) (a). Emergencies and family tracing and family reunification. Save the Children: Sweden. 
Save the Children Alliance Sweden (n.d) (b). Emergencies and children's physical environment. Sweden: Save the Children Alliance.

Save the Children (n.d) (c). Emergencies and psychosocial care and protection of affected children. Sweden: Save the Children.

Save the Children (n.d). Forgotten Casualties of War: Girls in Armed Conflict. Save the Children.

Snow, K. (2006). Vulnerable Citizens: The Oppression of Children in Care. Journal of Child and Youth Care Work. 21, 24-112.

UNICEF (2005). Core commitments for children in emergencies. UNICEF: New York.

UNICEF (2006). The 2004 Indian Ocean Tsunami Disaster: Evaluation of UNICEF's response (emergency and initial recovery phase). UNICEF: New York.

UNICEF (2007). Vitamin A supplementation: A decade of progress. UNICEF: New York.

UNICEF, International Federation of Red Cross and Red Crescent Societies, International Committee of the Red Crescent Societies (n.d). WHO, UNICEF, the International Committee of the Red Cross and the International Federation of Red Cross and Red Crescent Societies call for support for appropriate infant and young child feeding in the current Asian Emergency, and caution about unnecessary use of milk products.

United Nations (1989). United Nations Convention on the Rights of the Child. Ottawa: Ontario: Government of Canada, Multiculturalism \& Citizenship Canada. 
Vargas-Barón, E., and Bernal Alarcón, H. (2005). From Bullets to Blackboards:

Education for Peace in Latin America and Asia. Inter-American Development Bank: Washington.

Washington State Department of Health (2006). Helping Children after a disaster. http://www.doh.wa.gov/phepr/handbook/hbk_pdf/children.pdf. Last updated October 2006. Retrieved June 22, 2007.

Wessels, M., and Monteiro, K. (2004) Healing the Wounds Following Protracted Conflict in Angola: A Community-based approach to assisting war-affected children. In Gielen U.P. Fish, D.M., and Draguns, J.G. (Eds.) Handbook of Culture, Therapy and Healing. Mahwah (pp.321-342) NJ and London: Lawrence Erlbaum Associates Publishers.

Williams, S., Personal Communication, January 4, 2007.

Williams, S. (2007). Workshop for Developing Capacities to Plan and Respond to Children's Needs During Emergencies. Grenada: UNICEF.

Williams, J.R, Hyder, T., and Nicolai, S. (2005). Save the Children’s Experience: ECD in Emergencies. Early Childhood Matters, Responses to young children in Emergency Situations. 124 (July).

World Health Organization (2001). How to address psychosocial reaction to catastrophe. (Psychosocial Support Resources Child Health in Emergencies). Switzerland, Geneva: Department of Mental Health and Substance Dependence. World Health Organization (2003). Consultation on Child health in complex emergencies. (Meeting Report). Switzerland, Geneva: World Health Organization. 


\section{Appendix A Chart of Selected International Organizations}

\begin{tabular}{|c|c|}
\hline Organization or Agency & $\begin{array}{l}\text { Brief Description of Organization's } \\
\text { activities and focus in Emergency Relief }\end{array}$ \\
\hline Save the Children Alliance & $\begin{array}{l}\text { Protection from: physical harm; } \\
\text { exploitation and gender based } \\
\text { violence; psychosocial distress; } \\
\text { recruitment into armed groups; } \\
\text { family separation; abuse related to } \\
\text { forced displacement; denial to } \\
\text { access education } \\
\text { - STOP Principle } \\
\text { - Reliance-base approach } \\
\text { - Community-based approach } \\
\text { - Use a UNCRC moral framework }\end{array}$ \\
\hline United Nations Children’s Fund & $\begin{array}{l}\text { - Funding for emergency } \\
\text { programming } \\
\text { - Core Commitments: health and } \\
\text { nutrition; water, sanitation and } \\
\text { hygiene; child protection; education; } \\
\text { and HIV/AIDS } \\
\text { - Mechanisms to facilitate core } \\
\text { commitments include: security; } \\
\text { fundraising and communication; } \\
\text { human resources; information } \\
\text { technology and telecommunications; } \\
\text { supply and logistics; and finance } \\
\text { and administration } \\
\text { - Use a UNCRC moral framework }\end{array}$ \\
\hline World Health Organization & $\begin{array}{l}\text { - Coordinates inputs from } \\
\text { organizations' technical departments } \\
\text { and governments to address core } \\
\text { health issues for: the assessment of } \\
\text { health risks; health coordination; } \\
\text { epidemic and nutritional } \\
\text { surveillance; control of preventable } \\
\text { causes of illness and death; access to } \\
\text { basic preventative and protection of } \\
\text { health workers; services and } \\
\text { structures; and human rights to } \\
\text { health and reducing the impact of } \\
\text { future crises }\end{array}$ \\
\hline
\end{tabular}




\begin{tabular}{|c|c|}
\hline $\begin{array}{l}\text { International Federation of the Red } \\
\text { Crescent Societies/ International Committee } \\
\text { of the Red Cross }\end{array}$ & $\begin{array}{ll}\text { - } & \text { Material assistance } \\
\text { - } & \text { Disaster preparedness } \\
\text { - } & \text { Readiness to reduce the impact of } \\
\text { - } & \text { Predicting and preventing disasters } \\
\text { - } & \text { Disaster management in relief } \\
\text { - } & \text { asm in relief to provide life saving } \\
\text { basictance, shelter, food, water, } \\
\text { needs } \\
\text { - Long-term reconstruction and } \\
\text { rehabilitation }\end{array}$ \\
\hline Bernard van Leer Foundation & $\begin{array}{ll}\text { - } & \text { Child- centered approach targeting } \\
\text { - } & \text { poverty } \\
\text { - } & \text { Provide early childhood care } \\
\text { - } & \text { Pre-primary classes } \\
\text { - } & \text { Use a UNCRC moral framework }\end{array}$ \\
\hline Christian Children's Fund & $\begin{array}{ll}\text { - } & \text { Child-centered approach targeting } \\
\text { - } & \text { poverty } \\
\text { - } & \text { Parenide early childhood care } \\
\text { - } & \text { Pre-primary classes } \\
\text { - } & \text { Use a UNCRC moral framework }\end{array}$ \\
\hline Plan International & $\begin{array}{ll}\text { - } & \text { Child-centered approach targeting } \\
\text { - } & \text { Poverty } \\
\text { - } & \text { Parental education } \\
\text { - } & \text { Pre-primary classes } \\
\text { - } & \text { Use a UNCRC moral framework }\end{array}$ \\
\hline
\end{tabular}

